\title{
Seasonal Induced Changes in Spinach Rhizosphere Microbial Community Structure with varying Salinity and Drought
}

A. Mark Ibekwe ${ }^{\mathrm{a}^{*}}$, Selda Ors ${ }^{\mathrm{b}}$, Jorge F.S. Ferreira ${ }^{\mathrm{a}}$, Xuan Liu ${ }^{\mathrm{a}}$, and Donald L. Suarez ${ }^{\mathrm{a}}$

${ }^{a}$ US Salinity Laboratory, USDA-ARS, 450 W. Big Springs Rd., Riverside, CA 92507, USA.

${ }^{\mathrm{b}}$ Ataturk University, Department of Agricultural Structures and Irrigation, Erzurum, 25240, Turkey

*Corresponding author:

Abasiofiok Mark Ibekwe

USDA-ARS-U. S. Salinity Laboratory

450 W. Big Springs Rd

Riverside, CA 92507.

Phone: 951-369-4828

Fax: 951-342-4964

E-mail: Mark.Ibekwe@ars.usda.gov

Key words: Salinity, seasonal changes, irrigated agriculture, soil microbial communities, temporal variability, wastewater 


\begin{abstract}
Salinity is a common problem under irrigated agriculture, especially in low rainfall and high evaporative demand areas of southwestern United States and other semi-arid regions around the world. However, studies on salinity effects on soil microbial communities are relatively few while the effects of irrigation-induced salinity on soil chemical and physical properties and plant growth are well documented. In this study, we examined the effects of salinity, temperature, and temporal variability on soil and rhizosphere microbial communities in sand tanks irrigated with prepared solutions designed to simulate saline wastewater. Three sets of experiments with spinach (Spinacia oleracea L., cv. Racoon) were conducted under saline water during different time periods (early winter, late spring, and early summer). Bacterial 16S V4 rDNA region was amplified utilizing fusion primers designed against the surrounding conserved regions using MiSeq® Illumina sequencing platform. Across the two sample types, bacteria were relatively dominant among three phyla-the Proteobacteria, Cyanobacteria, and Bacteroidetes-accounted for $77.1 \%$ of taxa detected in the rhizosphere, while Proteobacteria, Bacteroidetes, and Actinobacteria accounted for $55.1 \%$ of taxa detected in soil. The results were analyzed using UniFrac coupled with principal coordinate analysis (PCoA) to compare diversity, abundance, community structure, and specific bacterial groups in soil and rhizosphere samples. Permutational analysis of variance (PERMANOVA) analysis showed that soil temperature $(P=$ $0.001)$, rhizosphere temperature $(P=0.001)$, rhizosphere salinity $(P=0.032)$, and evapotranspiration $(P=0.002)$ significantly affected beta diversity of soil and rhizosphere microbial communities. Furthermore, salinity had marginal effects $(P=0.078)$ on soil beta diversity. However, temporal variability differentially affected rhizosphere microbial communities irrigated with saline wastewater. Therefore, microbial communities in soils
\end{abstract}


impacted by saline irrigation water respond differently to irrigation water quality and season of application due to temporal effects associated with temperature.

\section{INTRODUCTION}

The southwestern United States and other semi-arid regions of the world are areas dominated by varying warming trends (frequency of heat waves and hot extremes/drought). Intensive agriculture is done in these regions with irrigation depending on limited available fresh water. A survey by the International Water Management Institute listed southwestern United States as water-stressed areas (Jimenez. 2008). Use of reclaimed waste water or other brackish waters may be a practical solution for fresh water scarcity in these regions, and has widely been used in arid and semi-arid regions of the world (Fahrenfeld et al., 2013). Currently, 70\% of fresh water supplies are used for irrigated agriculture (Hong et al., 2013), and this consumptive use is not sustainable in most semi-arid regions. Given that applications like agricultural and landscaping irrigation do not generally require high quality water supply, reuse of treated waste water can be an attractive option for conserving and extending available water supply (Hong et al., 2013). However, there are many problems associated with reclaimed water that may hinder its use for agricultural irrigation.

Salinity is one of these problems, and is frequently the single most important parameter determining the suitability of recycled water for agricultural irrigation (USEPA, 2004). To make matters worse, the increase in drought due to changes in weather patterns has exacerbated the problem of salinity (Froelich et al., 2012) and increased concentrations of pathogens during waste water discharge due to reductions in water levels (Senhorst \& Zwolsman, 2005). Salinity affects plants and microbes via two primary mechanisms: osmotic effect and specific ion toxicity (Oren, 1999; Chhabra 1996). Another factor influencing plants and microbes is soil water 
content. Soil water potential, which relates to the energy level by which the water is held in the soil also correlates to soil salinity, and it is influenced by osmotic potential in the soil solution. Drought can also result in increased salinity of surface waters (Froelich et al., 2012), and cause increases in soil surface hydrophobicity resulting in greater transport of surface runoffs (Boxall et al., 2009). Therefore, the combined problem of salinity and drought is enormous in the southwestern USA and other arid and semi-arid regions of the world. In fact, drought and salinity are the most important environmental factors limiting the yield of agricultural crops worldwide (McWilliam 1986). Global limitations of fresh water has increased the need to reuse agricultural, municipal, and industrial waters, some of which have high concentrations of $\mathrm{Na}^{+}$ and $\mathrm{Cl}^{-}$that will lead to reduced crop yield. The shortage of water caused by drought and the high electrical conductivity (EC) of degraded waters has raised the interest of farmers on how to grow high-value crops, such as spinach, with reused irrigation waters.

The inhibitory effect of high concentrations of salts on microbial processes is a combination of both the effects of highly negative osmotic potential and of specific ion toxicity. Recently, Rath et al. 2016 conducted a comparative study of the effects of toxicities of different salts, in terms of both total ionic strength (electric conductivity) and molar concentrations of added salts to disentangle the influence of osmotic potential and specific ion toxicity to soil microbial processes. Their findings suggested a lower toxicity of $\mathrm{SO}_{4}{ }^{2-}$ salts than of $\mathrm{Cl}^{-}$salts, at a similar ionic strength, for microbial respiration rates but not for growth rates for a short-term study of less than 24 hours. In most saline soils of the semi-arid and arid regions of the world, changes in salinity would be more gradual, and microbial communities would have more time to adapt, resulting in communities that can carry out the necessary microbial functions. However, microbial activities have been shown to remain reduced in soils that experienced high salt 
concentrations for longer periods of time (Wichern et al., 2006; Sardinha et al ., 2003,

Setia and Marschner 2013, Rath and Rousk 2015), though the direct effect of salinity remain unclear. Microorganisms that occur in naturally saline habitats are supposed to share a strategy for resisting to high salt concentrations, and to have developed multiple adaptations for maintaining active populations and cope with such extreme environmental conditions (Ma and Gong 2013). These authors have recently updated the available information on DNA sequences gained from a wide array of studies on soil microorganisms in saline environments, and also showed that there is a significant gap in the published information on the relevant soil properties where the microbial communities were sampled.

The effects of salinity may be more pronounced in the rhizosphere pursuant to increased water uptake by the plants due to transpiration. The simple explanation for this is that life in high salt concentrations is bioenergetically taxing because microorganisms must maintain an osmotic balance between their cytoplasm and the surrounding medium while excluding sodium ions from the cell interior, and as a result, sufficient energy is required for osmoadaptation (Oren et al., 2002; Jiang et al 2007). During our previous study using the same sand tanks, analyses of bacterial diversity showed that the effects of salinity, boron, and $\mathrm{pH}$ were more severe on the rhizosphere bacterial population during the first week of growing cucumber, with decreasing impacts with plant growth (Ibekwe et al 2010). This study suggested that the effects of salinityB-pH interactions may influence microorganisms first before plants and may pose long term effects on soil quality. Furthermore, the abundance and diversity of Cyanobacteria were higher in pre-plant soil with higher salinity but dropped significantly in the control soil (low salinity), probably in favor of species that were better adapted to lower salinities and salinity fluctuations. The trend was that the longer the soil was exposed to high salinity gradient the greater the 
reduction in Cyanobacterial abundance and diversity. The same trend was shown in the Bacteroidetes group, which was more abundant and diverse in the control soil with low salinity. It was also interesting to note that higher abundance of Deltaproteobacteria were more predominant in soil with higher salinity, whereas Alpha and Gammaproteobacteria were more predominant in control soil with low salinity. A related study from Australia concluded that salinity may affect rhizosphere microbial community structure indirectly through root exudates quantity and / or quality than directly through microbial toxicity, and that plant health was a major determinant in rhizosphere microbial community (Nelson and Mele, 2007). They showed a significant decrease in diversity and species richness in high saline rhizosphere soil and suggested that salinity affected utilization of several individual substrates as an indication of plant stress.

In this study we investigated the responses of soil and rhizosphere microbial community composition to increases in salinity and drought associated with high temperature in the southwestern United States. Microbial communities in high-temperature environments are often dominated by a few types of microorganisms, and are often significantly less diverse than those in lower temperature habitats (Benson et al., 2013). Temperature is likely a strong factor influencing microbial community structure (Li et al., 2015). This interpretation was supported by the results of CARD-FISH and qPCR study of soil samples collected along a steep thermal gradient $\left(50-90^{\circ} \mathrm{C}\right)$ in the Tengchong Geothermal Field (Li et al., 2015). The numbers of microorganisms were highest in the relatively low-temperature samples. The microorganism numbers correlated negatively with temperature. They suggested the possibilities that the low-temperature environment may provide some growth factors that are 
essential for microbial cells. We hypothesized that bacterial community composition across the plots (sand tanks) will change across different growing seasons in response to increases in temperature and salinity in spinach rhizosphere and bulk soil. Three experiments were conducted during late autumn, early winter, and late spring to coincide with spinach growing season in the southwestern United States. By using these three seasons, we aimed to answer 1) how richness and community composition of bacteria change in response to increases in temperature and salinity stress; and 2) whether these responses are similar throughout the planting seasons.

\section{Material and Methods}

\section{Experimental treatments}

The first and second set of experiments started on 7 December 2013 and 1 April 2014, respectively, in outside large sand tanks (Ors and Suarez. 2016) included salinity, drought and salinity drought treatments. Seeds were planted in sand culture tanks at $10 \mathrm{~cm}$ apart in three rows with $40 \mathrm{~cm}$ between rows. Seedlings were subsequently thinned to 25 plants per row. The sand culture tanks $(1.5 \times 3 \times 2 \mathrm{~m}$ deep) were filled with sand mixed with $10 \%$ peat moss (on volume basis) with an average bulk density of $1.38 \mathrm{~g} \mathrm{~cm}^{-3}$ (Dias et al., 2016: Fig. S1). At saturation, the sand had an average volumetric water content of $0.30 \mathrm{~m}^{3} \cdot \mathrm{m}^{-3}$. Each plot was irrigated with solutions prepared in an individual reservoir (1.5 m diameter $\times 2.2 \mathrm{~m}$ deep). Irrigation water (nutrient/control and nutrient/salt solutions) was pumped from water reservoirs (Vol=3,605L)

housed underneath the tank facility to the sand tanks above, completely saturating and leaching the sand culture medium. In each tank, the nutrient/salt solution returned to the reservoir, after 
each irrigation, through a subsurface drainage system at the bottom of the tanks, thus maintaining an essentially uniform and constant salinity in the root zone. (Dias et al., 2016: Fig. S1).

The third experiment was conducted in smaller sand tanks (Poss et al., 2004) consisting of 24 experimental plant growth units ( $81.5 \mathrm{~cm}$ wide $\mathrm{x} 202.5 \mathrm{~cm}$ long $\mathrm{x} 85 \mathrm{~cm}$ deep) containing sand with an average bulk density of $1.4 \mathrm{~g} \mathrm{~cm}^{-3}$ at the U. S. Salinity Laboratory in Riverside, CA to determine the effects of salinity and temperature on the rhizosphere and non-rhizosphere microbial composition of spinach (Spinacia oleracea L., cv. Racoon). Planting of spinach was done on 9 April, $10 \mathrm{~cm}$ apart and $30 \mathrm{~cm}$ between rows. Twenty-four sand tanks, arranged in a randomized complete design were irrigated from individual reservoirs containing a modified half-strength Hoagland's nutrient solution combined with various salinity levels. Each tank was plumbed with PVC pipes, one for irrigation to the sand tank, and one for return flow to a 1740-L reservoir in the basement below. Both small and large tanks utilized similar irrigation systems, enabling us to maintain an essentially uniform and constant salinity in the root zone. Initial irrigations consisted of nutrient solution made up in Riverside tap water to flush the system. The nutrient solution utilized a modified version of a half Hoagland's solution with (in mM): $2.5 \mathrm{Ca}$ $\left(\mathrm{NO}_{3}\right)_{2}, 3.0 \mathrm{KNO}_{3}, 0.17 \mathrm{KH}_{2} \mathrm{PO}_{4}, 1.5 \mathrm{MgSO}_{4}, 0.05 \mathrm{Fe}$ as sodium ferric diethylenetriamine pentaacetate (NaFe-EDTA), $0.023 \mathrm{H}_{3} \mathrm{BO}_{3}, 0.005 \mathrm{MnSO}_{4}, 0.0004 \mathrm{ZnSO}_{4}, 0.0002 \mathrm{CuSO}_{4}$, and $0.0001 \mathrm{H}_{3} \mathrm{MoO}_{4}$. The base nutrient solution without added salts served as the non-saline control $\left(\right.$ EC $\left.0.85 \mathrm{dS} \mathrm{m}^{-1}\right)$ in all experiments. 
The target electrical conductivities of the irrigation waters $\left(\mathrm{EC}_{\mathrm{i}}\right)$ of $4,7,9,12,15 \mathrm{dS} \mathrm{m} \mathrm{m}^{-1}$ were achieved by adding $\mathrm{CaCl}_{2}, \mathrm{MgCl}_{2}, \mathrm{NaCl}_{2}, \mathrm{Na}_{2} \mathrm{SO}_{4}$ to the base tap water-nutrient solution. Salt concentrations used were based on UNSATCHEM model (Suarez and Simunek, 1997) to predict the ion composition needed to achieve the target EC values. Salinity treatments started after the first pair of true leaves was fully expanded on all the plants. To avoid osmotic shock to the seedlings, salt was added in four equal increments over a four day period. Tanks were irrigated once daily for large tanks and twice for small tanks to completely saturate the sand culture in the non-drought treatments. The first experiment was a randomized design with three replications and four salinity treatments including control at $0.85 \mathrm{dS} \mathrm{m}{ }^{-1}$ ) and two different water types dominated by sulfate and chloride ion. The second and third experiments had 6 different EC levels including control treatment $\left(<0.85 \mathrm{dS} \mathrm{m}^{-1}\right)$ and only chloride ion water type. In these subsequent experiments we used only chloride water type since the first experiment did not show any statistical differences in spinach yields at any salinity levels between sulfate and chloride water types. Chemical composition of the salinity treatments used in the experiments has recently been reported (Ors and Suarez, 2016). The concentrations of $\mathrm{Na}, \mathrm{K}, \mathrm{Mg}, \mathrm{Ca}$, and total- S on the rhizosphere and non-rhizosphere samples were determined from nitric acid digestions by inductively coupled plasma optical emission spectrometry (ICP-OES).

\section{Drought treatments}

Soil moisture was recorded by 5-cm long moisture sensors (5TE probes, Decagon, Pullman, WA) attached to an Em50 data logger (Decagon). The soil moisture measurements were then converted to matric potential based on laboratory characterization of a moisture retention curve 
(theta vs matric potential) of the material (Ors and Suarez, 2016). Drought treatments were designed with soil water matric pressure as control treatment D0 (field capacity, $-33 \mathrm{kPa}$ ), treatment D1 (-200 to $-300 \mathrm{kPa})$, and treatment D2 (-400 to $-500 \mathrm{kPa})$. Drought D1 and D2 were imposed by providing less water, and irrigating less frequently than control D0, in accordance to instrument readings to keep matric potential within the specified limits (in $\mathrm{kPa}$ ) mentioned above. The average temperatures $\left({ }^{\circ} \mathrm{C}\right)$ and reference evapotranspiration $\left(\mathrm{ET}_{0}\right)$ that occurred during the experiment was acquired from the California Irrigation Management Systems (CIMIS) weather station no. 44 at University of California Riverside (Fig. 1), and the optimal temperature for growth of spinach in California (Koike et al.,2011).

\section{DNA extraction and V4 16S Illumina MiSeq sequencing}

The rhizosphere samples were collected after shaking loosely held soil on the roots into stomacher bags and weigh. Ten $\mathrm{g}$ of non-rhizosphere samples were collected at least $10 \mathrm{~cm}$ away from plants. Community DNA was extracted from rhizosphere and non-rhizosphere samples with the Power soil DNA Kit (MoBio Laboratories, Solana Beach, CA) and stored at $-20^{\circ} \mathrm{C}$ after further cleanup steps with DNA Clean and Concentrator (Zymo Research Corp- Irvine CA). Extracted DNA $(2 \mu \mathrm{L})$ was quantified using a Nanodrop ND-2000 C spectrophotometer (Nanodrop Technologies, Wilmington DE), and run on 1.0\% agarose gel before used for V4 16S Illumina MiSeq sequencing. DNA was extracted from each triplicate soil sample, and pooled for the sequencing step. Hence each pooled DNA contained samples from triplicate sand tanks. Microbiota from rhizosphere and non-rhizosphere samples were profiled using Second Genome’s Microbiome Signature Discovery service (San Bruno, CA, USA), Illumina sequencing assays to track microbial population dynamics across the three planting seasons. All samples were quantified via the Qubit Quant-iT dsDNA High Sensitivity Kit (Invitrogen, Life 
Technologies, Grand Island, NY) to ensure that they met minimum concentration and mass of DNA. The V4 region of the $16 \mathrm{~S}$ rRNA genes was amplified using fusion primers 515F (5'GTGCCAGCMGCCGCGGTAA-3') and 806R (5'-GGACTACVSGGGTATCTAAT-3')

(Caporaso et al., 2011), and then pooled for sequencing using the MiSeq (Illumina, San Diego, CA, USA) instrument.

\section{Statistical analysis of sequence data.}

Using the software QIIME (Kuczynski et al., 2011), UCLUST (Edgar, 2010) and MOTHUR (Schloss et al., 2009), sequences were clustered into reference OTUs and assigned taxonomic classification from the Greengenes database (McDonald et al., 2012). Sequenced paired-end reads were merged, quality filtered, and dereplicated with USEARCH (Edgar, 2013). Resulting unique sequences were then clustered at 97\% similarity by UPARSE (de novo OTU clustering) and a representative consensus sequence per de novo OTU was determined (Edgar, 2013). The clustering algorithm also performs chimera filtering to discard likely chimeric OTUs. Sequences that passed quality filtering were then mapped to a set of representative consensus sequences to generate an OTU abundance table. Representative OTU sequences were assigned taxonomic classification via mothur's bayesian classifier at $80 \%$ confidence; the classifier was trained against the Greengenes reference database of 16S rRNA gene sequences clustered at 99\%. After the taxa were identified for inclusion in the analysis, the values used for each taxa-sample intersection were populated with the abundance of reads assigned to each OTU in an OTU table. A corresponding table of OTU Greengenes classification was generated as well. Alpha-diversity (within sample diversity) metrics was calculated to estimate sample richness and Shannon diversity. Beta-diversity (sample-to-sample dissimilarity) metrics was calculated for the inter- 
comparison in a pair-wise fashion to determine dissimilarity score and store it in a distance dissimilarity matrix. Abundance-weighted sample pair-wise differences were calculated using the Bray-Curtis dissimilarity. All analyses were generated using Second Genome R package (vegan: R package version 2.2-1). Bray-Curtis dissimilarity was calculated by the ratio of the summed absolute differences in counts to the sum of abundances in the two samples using the Jaccard index. Hierarchical clustering maps of the samples in the form of dendrograms and principal coordinate analysis $(\mathrm{PCoA})$ were used to visualize complex relationships between samples. Permutational analysis of variance (PERMANOVA) was utilized to find significant differences among discrete categorical or continuous variables based on Monte Carlo permutation test. Univariate differential abundance of OTUs was tested using negative binomial noise model for the over dispersion and Poisson process intrinsic to this data, as implemented in the DESeq2 package (Love et. al. 2014), and described for microbiome applications in (McMurdie and Holmes 2013).

\section{Results}

Bacterial V4 16S rRNA gene analysis was performed to characterize the microbial communities associated with rhizosphere and soils impacted by salinity and drought. After processing and chimera removal, the average number of sequences was $457509( \pm 128753)$ for soil and $290327( \pm 94705)$ for rhizosphere. The sequences were grouped into different OTUs at 97\% identity and OTUs in soils for the three planting seasons were significantly $(P=0.001)$ higher than OTUs in the rhizosphere, with the highest OTU in March from soil sample and the lowest in June from rhizosphere samples (Table 1). Coverage was between 92 and $96 \%$ for each of the sample types (bulk soil and rhizosphere for the three planting seasons). Also, Shannon 
diversity $\left(H^{\prime}\right)$ was significantly higher $(P=0.001)$ in soil than in the rhizosphere. Across the two sample types, bacteria were relatively dominant by three phyla-the Proteobacteria, Cyanobacteria, and Bacteroidetes-accounted for $77.1 \%$ of taxa detected in the rhizosphere, while Proteobacteria, Bacteroidetes, and Actinobacteria accounted for 55.1\% of taxa detected in soil (Table 2). At the family level, five bacterial taxa were relatively dominant in the rhizosphere (Flavobacteriaceae, Halomonadaceae, Pseudomonadaceae, Sphingomonadaceae, and Comamonadaceae), and these taxa were about two- to three-fold higher in relative percent concentrations in the rhizosphere than in the non-rhizosphere samples (Table 2).

\section{Rhizosphere microbiomes response to salinity and temperature}

The influence of salinity on rhizosphere microbial communities during the three planting seasons was separated based on PCoA of OTUs (97\% 16S rRNA identity), indicating that there was a significant salinity effect on community composition (PERMANOVA for rhizosphere salinity $P$ $=0.032$; Figure $2 \mathrm{~A}$ ) calculated from the dimensional reduction of the Bray-Curtis distance between microbiome samples, using the PCoA ordination method. Samples were separated by month along the primary axis (Axis 1) and secondary axis (Axis 2), and 63.8\% of the sample variation was explained by the two major axes. Hierarchical clustering analysis by the ward method and Bray-Curtis distance showed that samples were clearly separated by months (Fig.2B). Bacterial composition at the family-level abundances did not show major differences among the eight major family members during the three seasons, indicating the overall composition of the community at low phylogenetic resolution did not change between these environments (Fig.2C) as a result of salinity.

Rhizosphere microbiomes were significantly $(P=0.001)$ affected by temperature (month of planting). Average air temperatures in the growing periods of experiment I, II and III were 
$11.9^{\circ} \mathrm{C}, 17.9^{\circ} \mathrm{C}, 20.15^{\circ} \mathrm{C}$, respectively. Samples were separated by month along the primary axis with $43.7 \%$ on PCoA 1 and $18.9 \%$ on PCoA2 resulting $62.6 \%$ of the sample variation being explained by the two major axes (data not shown). The effects of temperature on eight major taxa at the family-level abundance were analyzed and were grouped according their relative abundances (Fig. 2D). The group designated as 'Others' contained $>40 \%$ of the taxa not included in Figure 2D, and this group occupied the top portion of Figure 1D. Data are presented from experiment I in March to experiment III in June with different salinity ranges. Unclassified members were the highest in May and lowest in March. Seasonality favored the proliferation of different bacterial families. Wilcoxon signed rank sums and mean relative abundances for family-level taxa between temperature groups (months) are provided in Tables 3-5. The influence of temperature on relative abundance at the family level were significantly different for the unclassified $(P=0.002)$, Flavobacteriaceae $(P=0.036)$, Comamonadaceae $(P=0.010)$, and Pseudomonadaceae $(P=0.010)$ between March and May (Table 3). The effect of temperature on rhizosphere bacterial composition between March and June was different from that of March and May. In June the temperature was on the average about $8{ }^{\circ} \mathrm{C}$ warmer than March and this significantly affected the eight major bacterial families except Sphingomonadaceae (Table 4). However, temperature effects on bacterial composition between May and June (Table 5) showed significant impacts on Flavobacteriaceae $(P=0.036)$, Halomonadaceae $(P=0.036)$,

Pseudomonadaceae $(P=0.036)$, Enterobacteriaceae $(P=0.036)$, and Cytophagaceae $(P=$ 0.036). It should be that taxa within Halomonadaceae are known for high thermal tolerance and adapted to growing in high salt concentrations (Vreeland 1992).

\section{Soil microbiomes response to salinity and temperature.}


Salinity was not a significant driver for microbial taxa composition beta-diversity using weighted ordination (Fig.3A) or hierarchical clustering (Fig. 3B) as samples from each month clustered together, indicating that there was no significant salinity effect on bacterial community composition (PERMANOVA for soil salinity $P=0.078$; Fig. 3A) calculated from the dimensional reduction of the Bray-Curtis distance between microbiome samples, using the PCoA ordination method. Samples separated by month along the primary axis (Axis 1) and secondary axis (Axis 2) as $62.6 \%$ of the sample variation was explained by the two major axes. Bacterial composition at the family-level abundances did not show major differences due to salinity among the eight major family members except Comamonadaceae $(P=0.031)$ during the three seasons (Fig.3C). As a result of high alpha diversity in soil samples, the top 8 most abundant families covered less than $50 \%$ of the total abundance in soil microbiomes. There were no significant differences in the eight major family taxa abundances between March and May (Table 6), but there were significant differences in relative abundances of Cytophageaceae ( $P=$ 0.001), Comamonadaceae $(P=0.001)$, Sphingomonadaceae $(\mathrm{P}=0.035)$, and Flavobacteriaceae $(\mathrm{P}=0.002)$, between March and June (Table 7). Soil microbial composition was significantly different for Cytophageaceae $(P=0.036)$, Comamonadaceae $(P=0.036)$, A4b ( $P=0.036)$, Hyphomicrobiaceae $(P=0.036)$, and Planctomycetaceae $(P=0.036)$ between May and June (Table 8). The effects of temperature on eight major taxa at the family-level abundance were analyzed and were grouped according their relative abundances (Fig. 3D). Because of high alpha diversity in soil samples, the top 8 most abundant families covered less than $50 \%$ of the total abundance in soil microbiomes. The relative abundances of Cytophageaceae, Comamonadaceae, A4b, Hyphomicrobiaceae and Planctomycetaceae were significantly different between May and June as discussed above. 
Daily mean evapotranspiration $\left(\mathrm{ET}_{0}\right)$ significantly $(P=0.022)$ affected soil microbial composition during the three growing periods. Daily mean evapotranspiration $\left(\mathrm{ET}_{0}\right)$ values of each experiment and growing periods as number of days was recently reported in a related study (Ors and Suarez, 2016). These authors showed that $\mathrm{ET}_{0}$ values showed seasonal differences in water demand among the experiments with very low $\mathrm{ET}_{0}$ value in experiment 1, averaging 1.96 $\mathrm{mm}$ during the first ten days. During experiments II and III the minimum $\mathrm{ET}_{0}$ values were 4.43 and 6.36, respectively. It should be noted that the average temperatures in the growing periods of experiment I, II and III were $11.9^{\circ} \mathrm{C}, 17.9^{\circ} \mathrm{C}$, and $20.15^{\circ} \mathrm{C}$, respectively. This resulted in the potential evapotranspiration (PET) decrease during the course of the experiments from 276.3, 240.6 and $202.1 \mathrm{~mm}$ with increasing temperature for experiment I, II and III, respectively. PERMANOVA analysis also showed that $\mathrm{Ca}(P=0.174), \mathrm{Cl}(P=0.383), \mathrm{Mg}(P=0.262), \mathrm{Na}(P$ $=0.161)$, and $\mathrm{SO}_{4}(P=0.091)$ did not significantly contribute to the beta-diversity of our samples.

\section{Discussion}

The average temperatures for spinach growth is between $15-20{ }^{\circ} \mathrm{C}$ (FES, 2005), and in this study, the average temperatures in the growing periods of experiment I, II and III were $5.94{ }^{\circ} \mathrm{C}$, $17.9^{\circ} \mathrm{C}, 20.15^{\circ} \mathrm{C}$, respectively (Fig. 1). This resulted in significant $(P=0.022) \mathrm{ET}_{0}$ effects on soil microbial composition during the three planting seasons due to differences in water demand. The growing period was therefore longest for the first experiment, shorter for the second experiment and shortest for the third experiment, consistent with the increasing temperature during the growing period of experiments I-III. Again, this resulted in a significant temperature effects on soil microbial composition $(P=0.001)$ and rhizosphere mocrobial composition $(P-$ 0.001). As recently reported (Ors and Suarez, 2016), during the first experiment, $\mathrm{ET}_{0}$ was very 
low during the first ten days, averaging $1.96 \mathrm{~mm} \mathrm{~d}^{-1}$. In contrast, the minimum $\mathrm{ET}_{0}$ values were 4.43 and $6.36 \mathrm{~mm} \mathrm{~d}^{-1}$ for experiments II and III, respectively. Therefore, growing period was the longest for the first experiment and shortest for the third experiment, while experiment II was intermediate. The high temperature corresponded with increasing solar radiation from experiment I to III while relative humidity was similar for the three experiments based on CIMIS weather station no. 44 at University of California Riverside.

In the present study a thorough evaluation of soil characteristics was supported by Illumina sequencing of the V4 16S rRNA gene region to investigate the bacterial community structure and diversity in rhizosphere and non-rhizosphere soils plant with spinach under different salinity stress condition in a semi-arid region of southern California. Traditionally, soil quality is associated with productivity, but recently it has been defined in terms of sustainability, that is, the capacity of the soil to absorb, store and recycle water, minerals and energy such that the production of the crops can be maximized and environmental degradation minimized (de Souza Silva and Fay, 2012).Thus preservation of soil quality is a critical factor for environmental sustainability and increases in microbial diversity is the major factor that can significantly impact soil quality and sustainability. In dry and hot climates, such as those found in most semi and arid regions, the low soil moisture content and soil salinity may be the most stressful factors for the soil microbial flora, and frequently occur simultaneously with drought (de Souza Silva and Fay, 2012). The effect of salinity-induced soil microbial communities has always been more pronounced in the rhizosphere due to the increase in water absorption by the plants due to transpiration. This is in agreement with our study, which shows significant effects of salinity on rhizoshere microbial community $(P=0.032)$. The simple explanation for this is that life in high salt concentrations has a high bio-energetic taxation, since the microorganisms need to maintain 
osmotic equilibrium between the cytoplasm and the surrounding medium for the exclusion of sodium ions from inside the cell, therefore requiring high energy for osmo-adaptation (Oren, 2002; Oren, 2012; Jiang et al, 2007). Salt requirement and tolerance may be temperaturedependent, with salt tolerance and requirement being enhanced at increased temperatures (Mullakhanbhai and Larsen 1975; Novitsky and Kushner 1975).

Most microorganisms have relatively restricted salt concentration range for growth, except Halomonas elongata, which is a well-known example of a bacterium that can adapt to life over the whole salt concentration range from near fresh water to halite saturation. (Vreeland et al., 1980). In this study many species in the genus Halomonas and in the family Halomonadaceae (Gammaproteobacteria) were found in our study both in the soil and in the rhizosphere samples throughout the three experiments. Their relative percent concentrations were significantly higher $(P=0.036)$ in June than in May in the rhizosphere, indicating higher salinity stress did not affect them (Table 5) despite temperatures being higher than in spring. Halophilic behavior is found all over the phylogenetic tree of the prokaryotes (Oren 2002, 2008, 2010), most halophilic bacteria characterized in this study belong to the Gammaproteobacteria, and some moderate halophiles in other subgroups of the Proteobacteria, the low $\mathrm{G}+\mathrm{C}$ and the high G+C Firmicutes, the Cyanobacteria, the Bacteroidetes, and the Actinobacteria.

Due to potential global warming, it is expected that some geographic areas such as the southwestern USA, will experience some increases in temperature, receive less springtime precipitation, and have more frequent and severe droughts (Karl et al., 2009), in turn leading to higher soil salinity. Physiological stress, such as drought, will ultimately result in decreased microbial diversity, favoring those organisms that are best adapted to the stress (Kohler et al., 2010). Losses in biodiversity are expected to occur due to climate change and these changes may 
lead to some unexpected consequences such as the proliferation of pathogenic species due to a lack of competitor organisms (Altizer et al., 2013). For example, a previous study found that soil with reduced microbial diversity allowed for increased survival of an introduced E. coli O157:H7 (van Elsas et al., 2007, 2011). In fact, the general ecological principle of prokaryotic diversity states that as the factors in the environment become more extreme, the species that might be harbored will be less diverse (Frontier, 1985; Andrei et al., 2015). At the moment, reproducibility of this pattern is uncertain for microbial communities; however, several studies have found evidence for a declining tendency in prokaryotic diversity along increasing salinity gradients (Benlloch et al., 2002; Hollister et al., 2010). Along these lines, drought may inhibit some populations of native soil microflora while allowing for some of the more resistant groups of pathogenic bacteria, such as Staphylococcus, Clostridium and Bacillus, to survive. These unwanted events will definitely impact the way agriculture would be practiced in most arid and semi-arid regions of the world. For instance soil salinity can increase during time of drought, and has been found to be negatively correlated to the survival rate of $E$. coli $\mathrm{O} 157: \mathrm{H} 7$ in soils from leafy-green producing areas of the southwestern USA (Ma et al., 2012). Other consequences of drought-like conditions, such as those brought on by longer and drier summers, can lead to increases in soil surface hydrophobicity and cause more material to be transported as runoff when rain finally does arrive (Boxall et al., 2009).

Understanding the effect of changes in salinity and water content on soil microorganisms is important for crop production, sustainable land use, and rehabilitation of saline soils (Yan et al., 2015). In this study, and other related studies using the sand tanks, the effects of soil salinity and water content on microbial communities above and below ground, and on plant growth, may provide some guidance unto future research into management of saline soils (Ors and Suarez, 
2016; Ibekwe et al., 2010). One of the most important challenges facing the scientific community today is predicting the outcome of global climate change on ecosystem functioning. However, there is a large body of evidence, as discussed in this study, that suggests that the increase in drought is likely to result in higher salinity in the drier regions of the world. Due to the complexity of soil microbial communities and the virtually infinite ways in which different climate drivers such as temperature, precipitation, $\mathrm{ET}_{0}$ and their interactions might affect soil microorganisms and their activities (Bardgett et al. 2008), the impact of drought and salinity on soil microbial communities seems difficult to impossible to predict with full certainty until we collect more long term data from both control and field data. As seen in this study, the impact of drought and salinity on microbial communities or changes in climate drivers in soil, may be mostly associated with the rhizosphere.

Bacterial composition at the family-level abundances in the rhizosphere did not show major differences among the eight major family members during the three seasons, suggesting the overall composition of the community at low phylogenetic resolution did not change significantly between these environments (Fig.2C) as a result of salinity. Thus, the changes in bacterial community composition as a result of salinity effects were primarily at a higher phylogenetic order. On the order hand the effect of temperature was significant among some of the major eight taxa, suggesting that temperature was a driving force at low phylogenetic resolution. Organismal classes preferentially found to be significant different during different temperature were Sphingomonadaceae, Flavobacteriaceae, Halomonadaceae, Pseudomonadaceae, Enterobacteriaceae, and Cytophagaceae. Bacterial community composition and functional potential may change subtly across gradients in the sand tanks due to salinity or temperature. While there are significant phylogenetic divergences between communities in the 
tanks due to temperature than salinity, the underlying mechanisms to this phylogenetic structuring remain unknown. We believe that the functional potential of natural bacterial communities in the sand tanks must be fully evaluated since they are continuously used as experimental units and as natural soil ecosystems for growing many crops since they were setup in 1995.

\section{Conclusion}

In this study, different concentrations of bacteria were found in soil and rhizosphere of spinach exposed to increasing concentrations of salt in irrigation water that ranged from $\approx 1.0$ to $15 \mathrm{dS} / \mathrm{m}$ of irrigation water during three seasons of production. According to our results, increasing soil and rhizosphere temperature significantly affected microbial composition. However, the effect of soil salinity on microbial composition was marginal, indicating that rhizosphere microbial community may experience salinity stress much faster than soil microbial population. During our study, March was cooler than both May and June; however, rhizosphere and soil microbiome samples in March and May were more similar than to those isolated in June. Rhizosphere microbial composition from both March and May samples contained high relative abundances of Flavobacteriaceae, while June samples contained high relative abundances of Halomonadaceae. However, soil microbial composition between May and June significantly differed in the relative abundances of Cytophagaceae, Comamonadaceae, A4b, Hyphomicrobiaceae, and

Planctomycetaceae. Therefore, temporal variability associated with temperature differentially affected soil and rhizosphere microbial community composition.

ACKNOWLEDGEMENTS - This research was supported by the 214 Manure and Byproduct Utilization Project of the USDA-ARS. We thank Damon Baptista for technical assistance. Mention of trade names or commercial products in this publication is solely for the purpose of 
providing specific information and does not imply recommendation or endorsement by the U.S. Department of Agriculture. The U.S. Department of Agriculture (USDA) prohibits discrimination in all its programs and activities on the basis of race, color, national origin, age, disability, and where applicable, sex, marital status, familial status, parental status, religion, sexual orientation, genetic information, political beliefs, reprisal, or because all or part of an individual's income is derived from any public assistance program.

\section{REFERENCES}

Altizer, S., Ostfeld, R.S., Johnson, P.T.J., 2013. Climate change and infectious diseases: from evidence to a predictive framework. Science (New York, NY). 341, 514-19.

Andrei, A.-S., Robeson, M.S., Baricz, A., Coman, C., Muntean, V., Ionescu, A., Etiope, G., Banciu, H.L.2015. Contrasting taxonomic stratification of microbial communities in two hypersaline meromictic lakes. ISME Journal. 9: 2642-2656.

Bardgett, R.D., Freeman, C., Ostle, N., 2008. Microbial contributions to climate change through carbon cycle feedbacks. ISME J. 2:805-814.

Benlloch, S., López-López, A., Casamayor, E.O., Øvreås, L., Goddard, V., Daae, F.L., et al. 2002. Prokaryotic genetic diversity throughout the salinity gradient of a coastal solar saltern. Environ. Microbiol. 4, 349-360.

Benson, C. A., Bizzoco, R. W., Lipson, D. A. \& Kelley, S. T. 2013. Microbial diversity in nonsulfur, sulfur and iron geothermal steam vents. FEMS Microbiol Ecol 76: 74-88.

Boxall, A.B.A., Hardy, A., Beulke, S., 2009. Impacts of climate change on indirect human exposure to pathogens and chemicals from agriculture. Environ Health Persp. 117,508514.

Caporaso, J.G., Lauber, C., Walters, W.A., Berg-Lyons, D., Lozupone, C.A., Turnbaugh, P.J et 
al. 2011. Global patterns of $16 \mathrm{~S}$ rRNA diversity at a depth of millions of sequences per sample. Proc. Natl. Acad. Sci. USA. 15, 4516-4522.

Chhabra, R. 1996. Soil salinity and water quality. Balkema, Rotterdam,The Netherlands.

de Souza Silva, C.M.M., Fay, E.F., 2012. Effect of Salinity on Soil Microorganisms, Soil Health and Land Use Management, Dr. Maria C. Hernandez Soriano (Ed.), ISBN: 978-953-307614-0, InTech, Available from: http://www.intechopen.com/books/soil-health-and-landusemanagement/effect-of-salinity-on-soil-microorganisms.

Dias, N.S., Ferreira, J. F.S., Liu, X., Suarez, D. L.2016. Jerusalem artichoke (Helianthus tuberosus, L.) maintains high inulin, tuber yield, and antioxidant capacity under moderately-saline irrigation waters. Industrial Crops and Products. 94: 1009-1024.

Edgar, R.C., 2010. Search and clustering orders of magnitude faster than BLAST. Bioinf. 26, $2460-2461$

Edgar, R.C., 2013. UPARSE: highly accurate OTU sequences from microbial amplicon reads. Nat. Methods 10: 996-998.

Fahrenfeld, N., Ma, Y., O'Brien, M., Pruden, A. 2013. Reclaimed water as a reservoir of antibiotic resistance genes: distribution system and irrigation implications. Front. Microbiol. 4,130. 10.3389/fmicb.2013.00130

FES, 2005. Spinach : Atlantic Provinces vegetable crops production guide, No. 1400A. Canada, Department of Agriculture, Fisheries and Aquaculture. Farm Extension Services.

Froelich, B.A., Williams, T.C., Noble, R.T., Oliver, J.D., 2012. Apparent loss of Vibrio vulnificus from North Carolina oysters coincides with a drought-induced increase in salinity. Appl. Environ. Microbiol. 78:3885-9. 
Frontier, S. 1985. Diversity and structure in aquatic ecosystems. Oceanography and Marine Biol. Annual Review. 23: 253-312.

Hellberg, R.S., Chu. E., 2015. Effects of climate change on the persistence and dispersal of foodborne bacterial pathogens in the outdoor environment: A review. Crit. Rev. Microbiol. DOI: 10.3109/1040841X.2014.972335

Hollister, E.B., Engledow, A.S., Hammett, A.J.M., Provin, T.L, Wilkinson, H.H., Gentry, T.J. 2010. Shifts in microbial community structure along an ecological gradient of hypersaline soils and sediments. ISME J. 4, 829-838.

Hong, P.-Y., Al-Jassim, N., Ansari, M.I., Mackie, R.I., 2013. Environmental and Public Health Implications of Water Reuse: Antibiotic resistant bacteria, and antibiotic resistance genes. Antibiotics. 2, 367-399.

Ibekwe, A.M., Poss, J.A., Grattan, S.R., Grieve. C.M., Suarez, D., 2010. Bacterial diversity in cucumber (Cucumis sativus) rhizosphere in response to salinity, soil pH, and boron. Soil Biology Biochem.42, 567-575.

Jiang, H., Dong, H., Yu, B., Liu, X., Li, Y., Ji, S., Zhang, C.L., 2007. Microbial response to salinity change in Lake Chaka, a hypersaline lake on Tibetan plateau. Environ. Microbiol. 9, 2603-2621.

Jimenez, B. Water reuse: 2008. An International Survey of Current Practice, Issues and Needs. IWA Publishing; London, UK: 2008.

Karl, T.R., Melillo, J.M., Peterson, T.C., 2009. Global climate change impacts in the United States. New York: Cambridge University Press. 
Kohler, J., Knapp, B.A., Waldhuber, S., 2010. Effects of elevated $\mathrm{CO}_{2}$, water stress, and inoculation with Glomus intraradicesor Pseudomonas mendocina on lettuce dry matter and rhizosphere microbial and functional diversity under growth chamber conditions. J. Soils Sed. 10:1585-97.

Koike, S.T., Cahn, M., Cantwell, M., Fennimore, S., Lestrange, M., Natwick, E., Smith, R.F., Takele, E., 2011. Spinach production in California. Ed. by University of California. Agric. Natural Res. Pub 7212.

Kuczynski, J., Stombaugh, J., Walters, W.A., González, A., Caporaso, J.G., Knight, R., 2011. Using QIIME to analyze 16S rRNA gene sequences from microbial communities. Curr Protoc. Microbiol ; Chapter 10:Unit 10.7. doi: 10.1002/0471250953.bi1007s36.

Li, H., Yang, Q., Li, J., Gao, H., Li, P., Zhou, H. 2015. The impact of temperature on microbial diversity and AOA activity in the Tengchong Geothermal Field, China. Sci. Rep. 5, 17056; doi: 10.1038/srep17056.

Love, M. I., Huber, W., Anders, S. 2014. Moderated estimation of fold change and dispersion for RNA-Seq data with DESeq2. bioRxiv. doi:10.1101/002832

Ma, B., Gong, J., 2013. A meta- analysis of the publicly available bacterial and archaeal sequence diversity in saline soils. World J. Microbiol. Biotechnol. DOI 10.1007/s11274013-1399-9.

Ma, J., Ibekwe, A.M., Crowley, D.E., Ching-Hong, Y., 2012. Persistence of Escherichia coli O157:H7 in major leafy green producing soils. Environ. Sci. Technol. 46, 12154-61.

McDonald, D., Price, MN, Goodrich, J, Nawrocki, EP, DeSantis, TZ, Probst, A, Andersen, 
GL, Knight R, and P. Hugenholtz. 2012. An improved Greengenes taxonomy with explicit ranks for ecological and evolutionary analyses of bacteria and archaea. ISME J. 6, 610-618.

McMurdie, P. J., Holmes, S. 2013. phyloseq: an R package for reproducible interactive analysis and graphics of microbiome census data. PLoS ONE. 8. e61217.

McWilliam, J,R., 1986. The national and international importance of drought and salinity effects on agricultural production. Func. Plant Biol. 13,1-13.

Mullakhanbhai, M.F., Larsen, H., 1975. Halobacterium volcanii spec. nov., a Dead Sea halobacterium with a moderate salt requirement. Arch. Microbiol. 104,207-214.

Nelson, D. R., Mele P. M., 2007. Subtle changes in the rhizosphere microbial community structure in response to increased boron and sodium chloride concentrations. Soil Biology and Biochemistry 39, 340-351.

Novitsky, T.J., Kushner, D.J., 1975. Influence of temperature and salt concentration on the growth of a facultatively halophilic “Micrococcus" sp. Can. J. Microbiol. 21,107-110

Oren, A., 1999. Bioenergetic aspects of halophilism. Microbiol. Mol. Biol. Rev. 63, 334-340

Oren, A., 2002. Molecular ecology of extremely halophilic archaea and bacteria. FEMS Microbiol. Ecol. 39, 1-7.

Oren, A., 2002. Diversity of halophilic microorganisms: environments, phylogeny, physiology, and applications. J. Indust. Microbiol. Biotechnol. 28,56-63.

Oren, A., 2008. Microbial life at high salt concentrations: phylogenetic and metabolic diversity. Sal. Syst 4:2

Oren, A., 2010. Diversity of halophiles. In: Horikoshi K, Bull A, Robb F, Stetter K, Antranikian 
G (eds) Extremophiles handbook. Springer, Tokyo.

Oren, A., 2013. Life at high salt concentrations. Rosenberg et a., (eds.)., The ProcharyotesProkaryotes Communities ans Ecophysiology.,Doi 10.1007/978-3-642-301230_57.Berlin Heidelberg.

Ors, S., Suarez, D.L., 2016. Salt tolerant of spinach as related to seasonal climate. Hort Sci. (Prague). 43, 33-41.

Poss, J., Russell, W., Shouse, P., Austin, R., Grattan, S., Grieve, C., Lieth, J., Zeng, L., 2004. A volumetric lysimeter system (VLS): An alternative to weighing lysimeters for plant-water relations studies. Computers and Electronics in Agric. 43: 5568.

Rath, K.M., Rousk, J., 2015. Salt effects on the soil microbial decomposer community and their role in organic carbon cycling: a review. Soil Biol Biochem81:108123. 10.1016/j.soilbio. 2014.11.001.

Rath, K.M., Maheshwari, A., Bengtson, P., Rousk, J., 2016. Comparative toxicities of salts on microbial processes in soil. Appl. Environ. Microbiol. 82, 2012-2020.

Sardinha, M., Müller, T., Schmeisky, H., Joergensen, R.G., 2003. Microbial performance in soils along a salinity gradient under acidic conditions. Appl. Soil Ecol. 23,237-244. 244.

Schloss, P.D., Westcott, S.L., Ryabin, T., Hall, J.R., Hartmann, M., Hollister, E.B et al. 2009. Introducing mothur: open-source, platform-independent, community-supported software for describing and comparing microbial communities. Appl. Environ. Microbiol. 75, $7537-7541$. 
Senhorst, H.A.J., Zwolsman, J.J.G., 2005. Climate change and effects on water quality: a first impression. Water Sci. Technol. 51, 53-9.

Setia, R., Marschner, P., 2013. Impact of total water potential and varying contribution of matric and osmotic potential on carbon mineralization in saline soils. Eur. J. Soil Biol. 56, 95100.

Suarez, D.L., Simunek, J., 1997. UNSATCHEM: Unsaturated water and solute transport model with equilibrium and kinetic chemistry. Soil Sci. Soc. Am. J., 61(5): 1633-1646.

USEPA. 2004. Guidelines for water reuse. EPA 625/R-04/108. USEPA, Cincinnati, OH.

van Elsas, J.D., Jansson, J.K., Trevors, J.T., 2007. Modern soil microbiology. Boca Raton (FL): CRC Press

van Elsas, J.D., Semenov, A.V., Costa, R., Trevors, J.T. 2011. Survival of Escherichia coli in the environment: fundamental and public health aspects. ISME J. 5:173-83.

Vreeland, R.H., Litchfield, C.D., Martin, E.L., Elliot, E., 1980. Halomonas elongata, a new genus and species of extremely salt-tolerant bacteria. Int. J. Syst. Bacteriol. 30, 485-495.

Wichern, J., Wichern, F., Joergensen, R.G., 2006. Impact of salinity on soil microbial communities and the decomposition of maize in acidic soils. Geoderma, 137, 100108. 10.1016/j.geoderma. 08.001 .

Yan, N., Marschner, P., Cao, W., Zuo, C., Qin. W., 2015. Influence of salinity and water content on soil microorganisms. Intern. Soil Water Con. Res. 3, 316-323 
Table 1. Mean (SD) values for alpha diversity metrics for each study group.

\begin{tabular}{lllll}
\hline Month & Type & OTUs & No of sequence & Shannon $\left(\mathrm{H}^{\prime}\right)$ \\
\hline June & root & $2527(289)$ & $195622(56288)$ & $4.16(0.437)$ \\
March & root & $3341(482)$ & $385032(68251)$ & $5.41(0.759)$ \\
May & root & $3087(542)$ & $326148(51268)$ & $4.78(0.945)$ \\
June & soil & $3328(432)$ & $420708(98552)$ & $6.19(0.321)$ \\
March & soil & $4548(231)$ & $586263(236332)$ & $6.59(0.508)$ \\
May & soil & $3498(206)$ & $504256(200235)$ & $6.42(0.162)$ \\
\hline
\end{tabular}

Soil salinity $(\mathrm{P}=0.078)$; root salinity $(\mathrm{P}=0.032)$, soil temperature $(\mathrm{P}=0.001)$, root temperature $(\mathrm{P}=0.001)$.

Table 2: Most abundant taxa at the phylum and family level.

\begin{tabular}{llllll}
\hline Phylum & Rhizosphere & $\begin{array}{l}\text { Non- } \\
\text { rhizosphere }\end{array}$ & Family & Rhizosphere & $\begin{array}{l}\text { Non- } \\
\text { rhizosphere }\end{array}$ \\
\hline Proteobacteria & $47.9(12.2)$ & $29.2(6.93)$ & unclassified & $10.9(10.2)$ & $3.96(5.76)$ \\
Cyanobacteria & $11.8(10.3)$ & $6.99(6.48)$ & Enterobacteriaceae & $3.31(5.78)$ & $0.992(3.37)$ \\
Bacteroidetes & $17.4(12.3)$ & $12.6(4.70$ & Flavobacteriaceae & $9.77(10.8)$ & $2.69(2.37)$ \\
Actinobacteria & $4.86(2.09)$ & $13.3(1.88)$ & Comamonadaceae & $7.86(4.36)$ & $3.51(1.86)$ \\
Chloroflexi & $3.66(1.66)$ & $9.64(4.08)$ & Pseudomonadaceae & $6.15(6.74)$ & $0.872(1.04)$ \\
Planctomycetes & $4.89(1.84)$ & $8.01(2.1)$ & Sphingomonadaceae & $6.42(2.11)$ & $3.14(1.31)$ \\
Acidobacteria & $2.73(2.15)$ & $5.95(1.91)$ & Halomonadaceae & $6.07(11.3)$ & $0.54(0.56)$ \\
Verrucomicrobia & $3.42(0.98)$ & $3.28(0.78)$ & Cytophagaceae & $3.21(2.25)$ & $3.81(1.81)$ \\
\hline
\end{tabular}

Table 3: Wilcoxon signed rank sum test for March and May on top 8 most abundant families affected by rhizosphere temperature.

\begin{tabular}{llll}
\hline Family & $\mathbf{P}<\mathbf{0 . 0 5}$ & March mean (sd)* & May mean $(\mathbf{s d})$ \\
\hline unclassified & 0.002 & $0.985(0.372)$ & $17.2(13.8)$ \\
Flavobacteriaceae & 0.036 & $17.9(14)$ & $11.5(12.6)$ \\
Comamonadaceae & 0.010 & $11.9(2.35)$ & $7.6(2.14)$ \\
Halomonadaceae & 0.58 & $0.407(0.0358)$ & $0.0808(0.061)$ \\
Sphingomonadaceae & 0.10 & $5.56(0.591)$ & $7.3(1.47)$ \\
Pseudomonadaceae & 0.010 & $5.19(2.98)$ & $0.269(0.157)$ \\
Enterobacteriaceae & 0.36 & $0.0291(0.0194)$ & $0.0471(0.0271)$ \\
Cytophagaceae & 0.20 & $5.75(2.44)$ & $3.25(0.982)$ \\
\hline
\end{tabular}

* Percent relative abundance means are provided. Average temperature in March was $15.94{ }^{\circ} \mathrm{C}$, May $17.9{ }^{\circ} \mathrm{C}$, June $20.15{ }^{\circ} \mathrm{C}$ 
Table 4: Wilcoxon signed rank sum test for March and June on top 8 most abundant families affected by rhizosphere temperature.

\begin{tabular}{llll}
\hline Family & $\mathbf{P}<\mathbf{0 . 0 5}$ & March mean (sd)* & June mean (sd) \\
\hline unclassified & 0.001 & $0.985(0.372)$ & $12.7(4.24)$ \\
Flavobacteriaceae & 0.001 & $17.9(14)$ & $1.07(0.234)$ \\
Comamonadaceae & 0.001 & $11.9(2.35)$ & $3.88(2.47)$ \\
Halomonadaceae & 0.001 & $0.407(0.0358)$ & $19.8(17.3)$ \\
Sphingomonadaceae & 1.00 & $5.56(0.591)$ & $6.09(3.1)$ \\
Pseudomonadaceae & 0.020 & $5.19(2.98)$ & $11.8(8.15)$ \\
Enterobacteriaceae & 0.001 .0 & $0.0291(0.0194)$ & $11.4(5.29)$ \\
Cytophagaceae & 0.010 & $5.75(2.44)$ & $1.09(0.436)$ \\
\hline
\end{tabular}

* Percent relative abundance means are provided. Average temperature in March was $15.94{ }^{\circ} \mathrm{C}$, May $17.9^{\circ} \mathrm{C}$, June $20.15^{\circ} \mathrm{C}$

Table 5: Wilcoxon signed rank sum test for May and June on top 8 most abundant families affected by rhizosphere temperature.

\begin{tabular}{llll}
\hline Family & $\mathbf{P}<\mathbf{0 . 0 5}$ & May mean (sd)* & June mean (sd) \\
\hline unclassified & 0.295 & $19.7(11.4)$ & $11.8(3.73)$ \\
Flavobacteriaceae & 0.036 & $10.7(9.81)$ & $1.21(0.325)$ \\
Comamonadaceae & 0.093 & $7.04(1.88)$ & $3.7(1.94)$ \\
Halomonadaceae & 0.036 & $0.773(1.42)$ & $17.4(14.1)$ \\
Sphingomonadaceae & 0.295 & $7.94(1.58)$ & $6.06(2.74)$ \\
Pseudomonadaceae & 0.036 & $0.434(0.304)$ & $13.2(6.75)$ \\
Enterobacteriaceae & 0.036 & $0.0363(0.0269)$ & $9.87(6.01)$ \\
Cytophagaceae & 0.036 & $2.91(0.942)$ & $1.2(0.393)$ \\
\hline
\end{tabular}

* Percent relative abundance means are provided. Average temperature in March was $15.94{ }^{\circ} \mathrm{C}$, May $17.9{ }^{\circ} \mathrm{C}$, June $20.15^{\circ} \mathrm{C}$

Table 6: Wilcoxon signed rank sum test for March and May on top 8 most abundant families affected by soil temperature.

\begin{tabular}{llll}
\hline Family & $\mathbf{P}<\mathbf{0 . 0 5}$ & March mean $(\mathbf{s d})^{*}$ & May mean $(\mathbf{s d})$ \\
\hline unclassified & 0.86 & $7.57(11.3)$ & $2.36(1.040$ \\
Cytophagaceae & 0.58 & $5.56(1.65)$ & $4.32(0.423)$ \\
Comamonadaceae & 0.10 & $5.79(1.69)$ & $3.77(1.21)$ \\
A4b & 0.10 & $1.00(0.169)$ & $5.28(1.02)$ \\
Sphingomonadaceae & 0.10 & $4.38(0.64)$ & $2.25(0.329)$ \\
Hyphomicrobiaceae & 0.10 & $2.78(0.416)$ & $4.20(0.528)$ \\
Flavobacteriaceae & 0.10 & $5.08(1.79)$ & $1.30(1.21)$ \\
Planctomycetaceae & 0.10 & $1.20(0.199)$ & $3.53(1.17)$ \\
\hline
\end{tabular}

* Percent relative abundance means are provided. Average temperature in March was $15.94{ }^{\circ} \mathrm{C}$, May $17.9^{\circ} \mathrm{C}$, June $20.15^{\circ} \mathrm{C}$ 
Table 7: Wilcoxon signed rank sum test for March and June on top 8 most abundant families affected by soil temperature.

\begin{tabular}{llll}
\hline Family & $\mathbf{P}<\mathbf{0 . 0 5}$ & March mean $(\mathbf{s d})^{*}$ & June mean $(\mathbf{s d})$ \\
\hline unclassified & 0.58 & $7.57(11.3)$ & $2.56(2.22)$ \\
Cytophagaceae & $\mathbf{0 . 0 0 1}$ & $\mathbf{5 . 5 6}(\mathbf{1 . 6 5})$ & $\mathbf{1 . 7 3}(\mathbf{0 . 2 1 9})$ \\
Comamonadaceae & $\mathbf{0 . 0 0 1}$ & $\mathbf{5 . 7 9}(\mathbf{1 . 6 9})$ & $\mathbf{1 . 9 6}(\mathbf{0 . 2 9 8})$ \\
A4b & 0.10 & $1.00(0.169)$ & $2.12(0.2410$ \\
Sphingomonadaceae & $\mathbf{0 . 0 3 5}$ & $\mathbf{4 . 3 8}(\mathbf{0 . 6 4})$ & $\mathbf{2 . 2 2}(\mathbf{0 . 7 4 1 )}$ \\
Hyphomicrobiaceae & 0.10 & $2.78(0.416)$ & $1.02(0.337)$ \\
Flavobacteriaceae & $\mathbf{0 . 0 0 2}$ & $\mathbf{5 . 0 8}(\mathbf{1 . 7 9 )}$ & $\mathbf{2 . 3 7}(\mathbf{2 . 6 5})$ \\
Planctomycetaceae & 0.20 & $1.20(0.199)$ & $1.86(0.589)$ \\
\hline
\end{tabular}

* Percent relative abundance means are provided. Average temperature in March was $15.94{ }^{\circ} \mathrm{C}$, May $17.9^{\circ} \mathrm{C}$, June $20.15{ }^{\circ} \mathrm{C}$

Table 8: Wilcoxon signed rank sum test for May and June on top 8 most abundant families affected by soil temperature.

\begin{tabular}{llll}
\hline Family & P $<\mathbf{0 . 0 5}$ & May mean $(\mathbf{s d}) *$ & June mean $(\mathbf{s d})$ \\
\hline unclassified & 0.208 & $2.36(1.470$ & $4.02(4.18)$ \\
Cytophagaceae & $\mathbf{0 . 0 3 6}$ & $\mathbf{4 . 3 8}(\mathbf{0 . 3 5 7})$ & $\mathbf{1 . 6 4}(\mathbf{0 . 2 3 8 0}$ \\
Comamonadaceae & $\mathbf{0 . 0 3 6}$ & $\mathbf{3 . 3 7}(\mathbf{1 . 1 3})$ & $\mathbf{1 . 7 4}(\mathbf{0 . 4 1 9})$ \\
A4b & $\mathbf{0 . 0 3 6}$ & $\mathbf{5 . 4 4}(\mathbf{0 . 8 7 5})$ & $\mathbf{2 . 0 6}(\mathbf{0 . 2 3 5})$ \\
Sphingomonadaceae & 0.834 & $2.35(0.30)$ & $2.33(0.658)$ \\
Hyphomicrobiaceae & $\mathbf{0 . 0 3 6}$ & $\mathbf{4 . 0 6}(\mathbf{0 . 4 8 6})$ & $\mathbf{0 . 9 5 6 ( 0 . 2 8 7 )}$ \\
Flavobacteriaceae & 0.402 & $1.16(0.973)$ & $2.02(2.13)$ \\
Planctomycetaceae & $\mathbf{0 . 0 3 6}$ & $\mathbf{3 . 4 2}(\mathbf{0 . 9 3 7})$ & $\mathbf{1 . 9 6}(\mathbf{0 . 7 1 5})$ \\
\hline
\end{tabular}

${ }^{*}$ Percent relative abundance means are provided. Average temperature in March was $15.94{ }^{\circ} \mathrm{C}$, May $17.9{ }^{\circ} \mathrm{C}$, June $20.15^{\circ} \mathrm{C}$ 


\section{Figure Captions:}

Figure.1. The average temperatures $\left({ }^{\circ} \mathrm{C}\right)$ from 1992-2013 was acquired from the California Irrigation Management Systems (CIMIS) weather station no. 44 at University of California Riverside. This period covers the period for this study from December 2012 to June 2013.

Figure 2: Weighted ordination in the rhizosphere: (A) Dimensional reduction of the Bray-Curtis distance between microbiome samples, using the PCoA ordination method. (B) Hierarchical Clustering by the ward method and Bray-Curtis distance (C) Most Abundant bacteria at the family level in the rhizosphere with no significant differences due to salinity. Spearman values are shown with relative abundance mean values with standard deviation (SD). (D) Top 8 most abundant families in root-temp comparison.

Figure 3. Weighted ordination in soil: (A) Dimensional reduction of the Bray-Curtis distance between microbiome samples, using the PCoA ordination method (B) Clustered by the ward method and Bray-Curtis distance (C). Plot shows the most abundant taxa at the Family level with no significant differences due to salinity except Comamonadaceae. Spearman values are shown with relative abundance mean values with standard deviation (SD) (D) Top 8 most abundant families in soil temp comparison.

Figure S1 - Schematic drawing of the outdoor lysimeter system with 24 outdoor tanks, each connected through PVC pipes and an electric pumping system, with 24 underground water reservoirs. The aerial view insert (lower left) shows tank area oriented N/S with four rows of six tanks each in a caged area of $418 \mathrm{~m}^{2}$. Vol = filled volume of reservoir. 


\section{Mean Monthly Temperatures, 1992-2013}

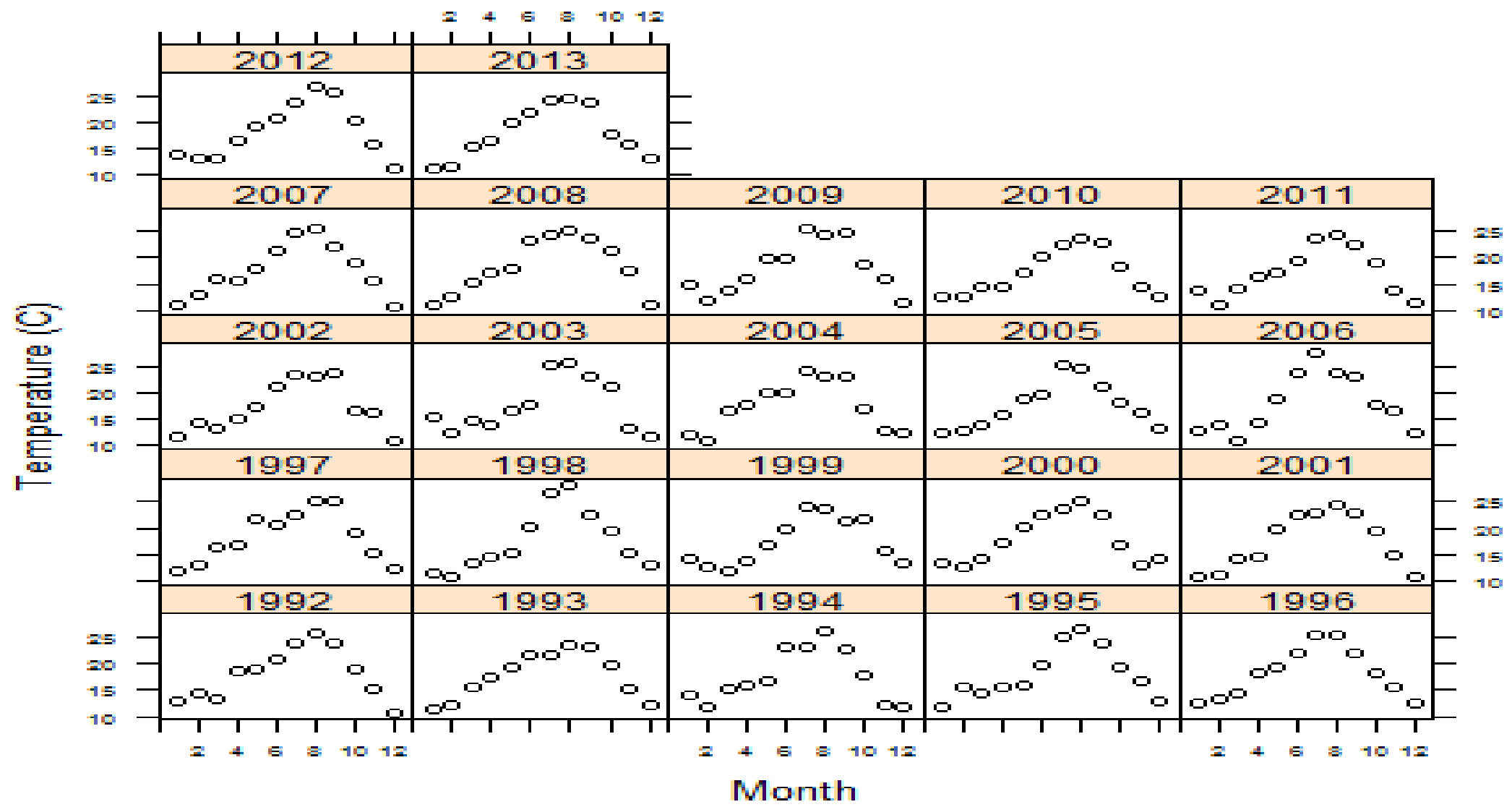

Fig.1 


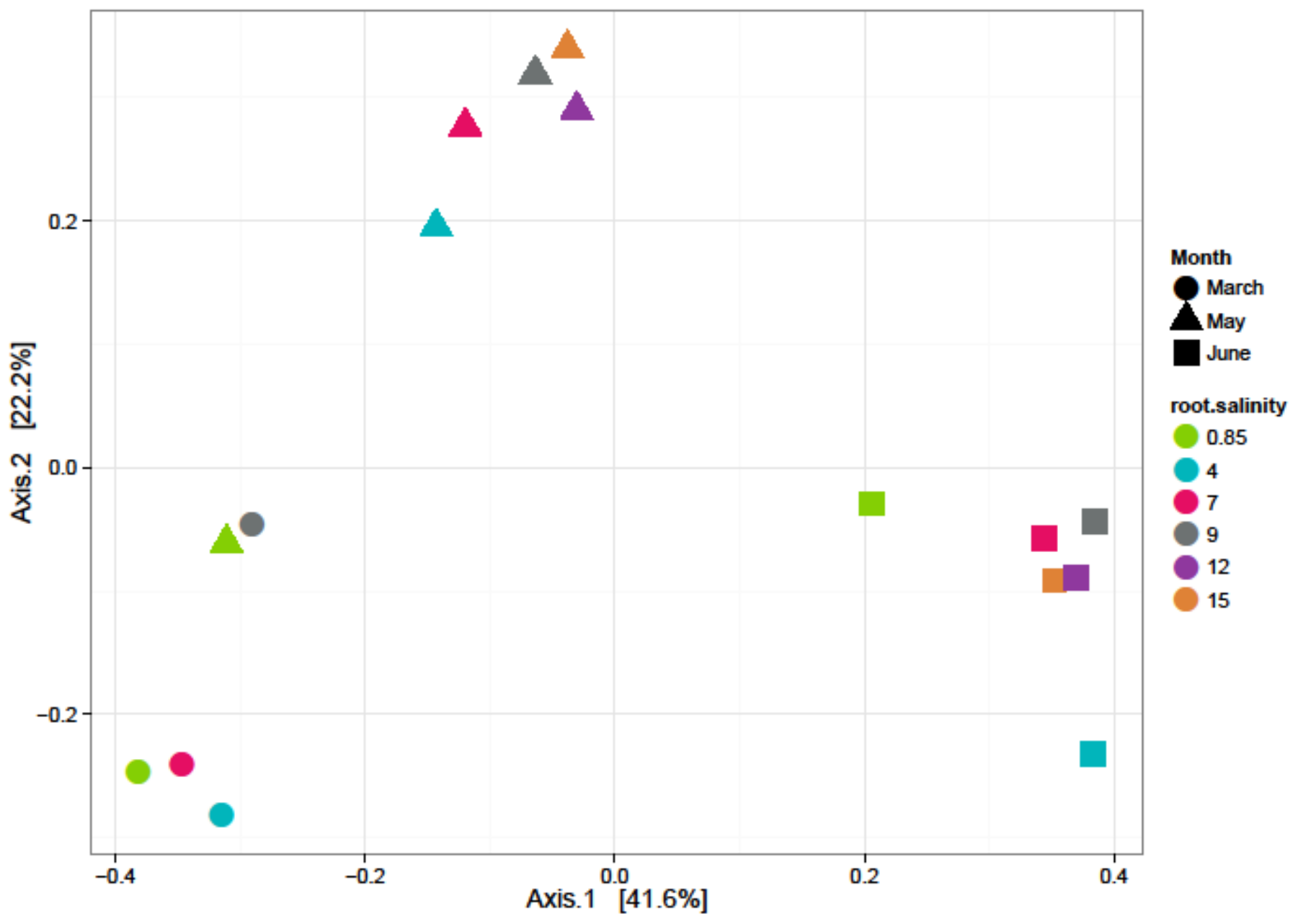

$2 \mathrm{~A}$ 


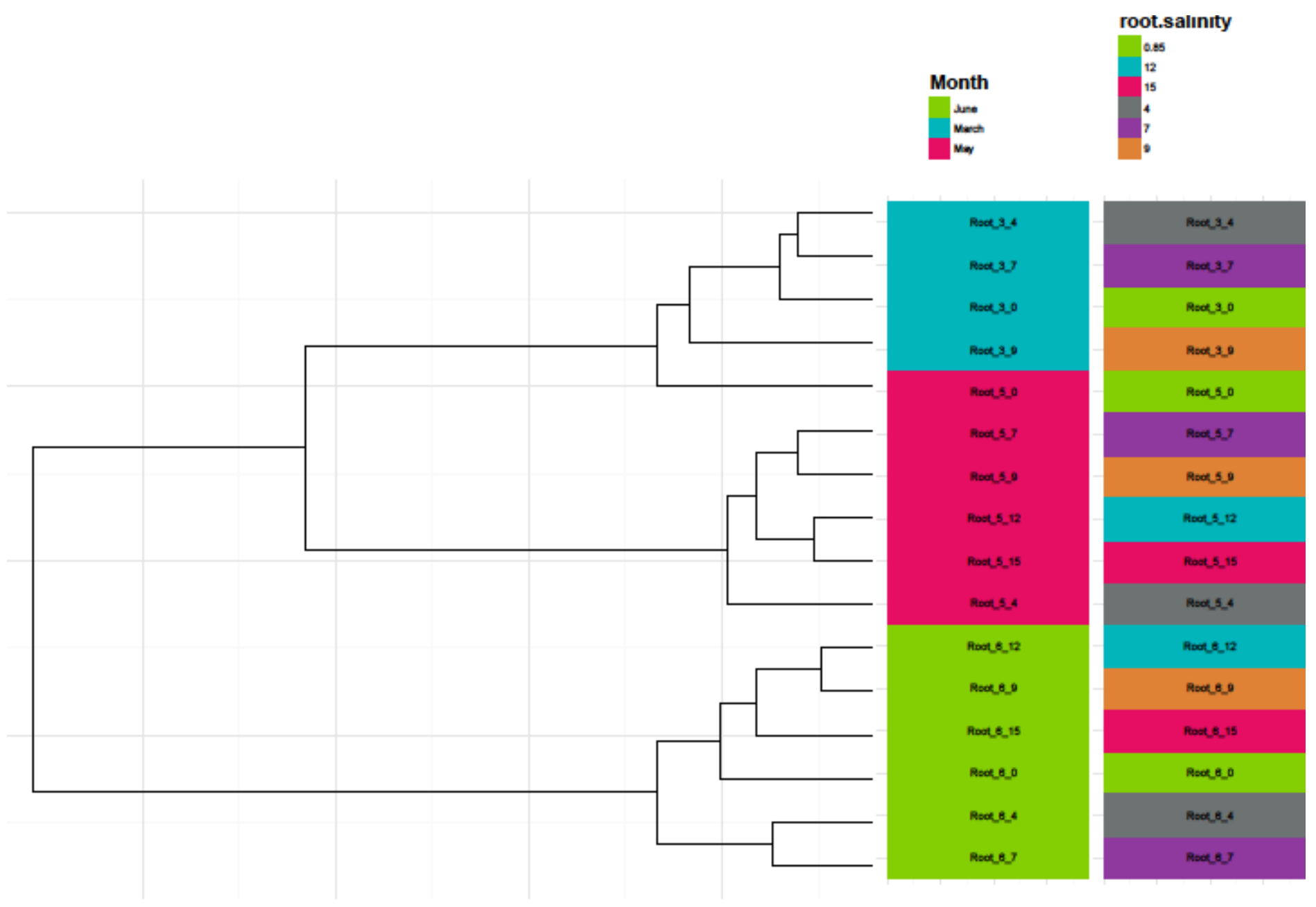




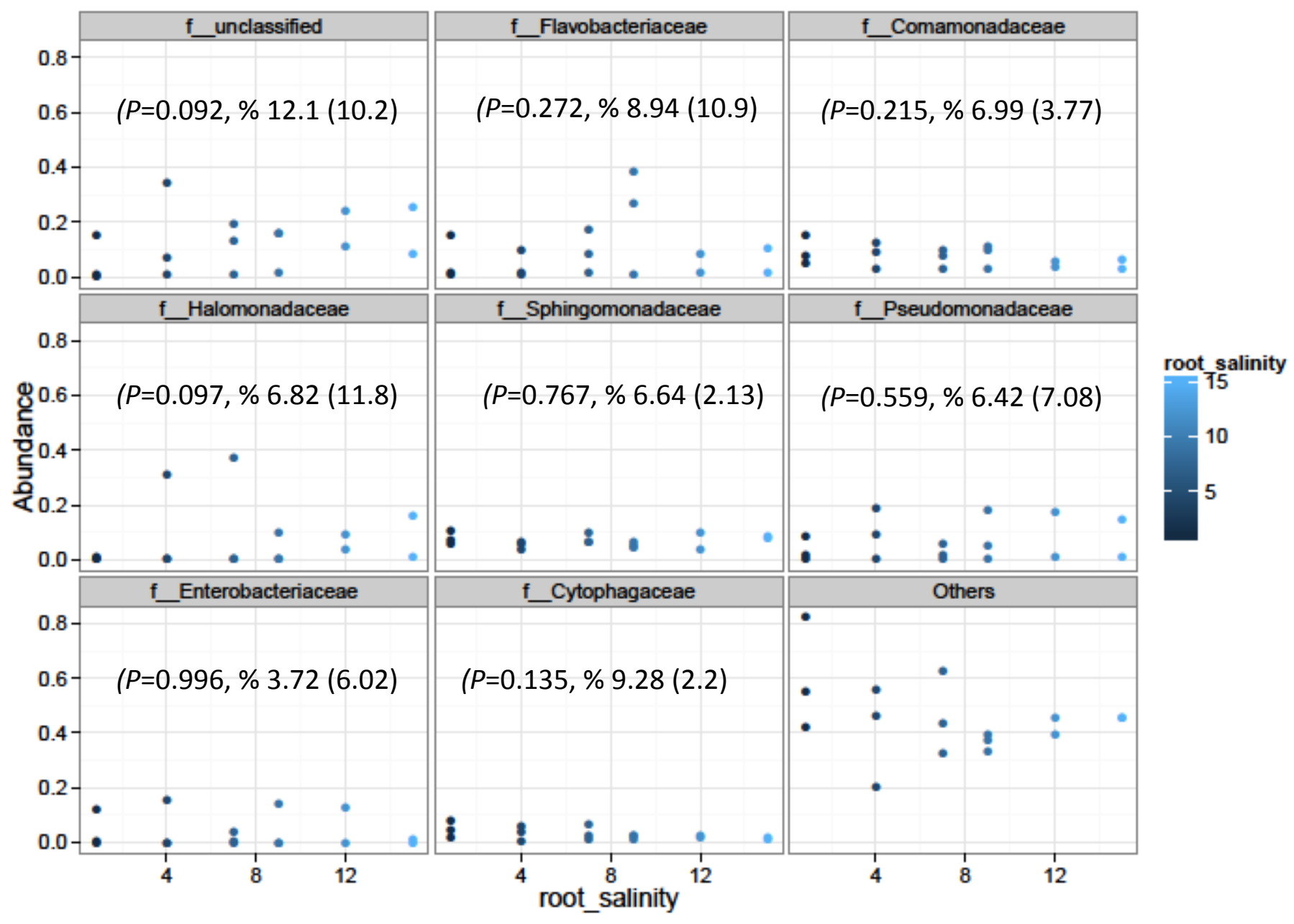




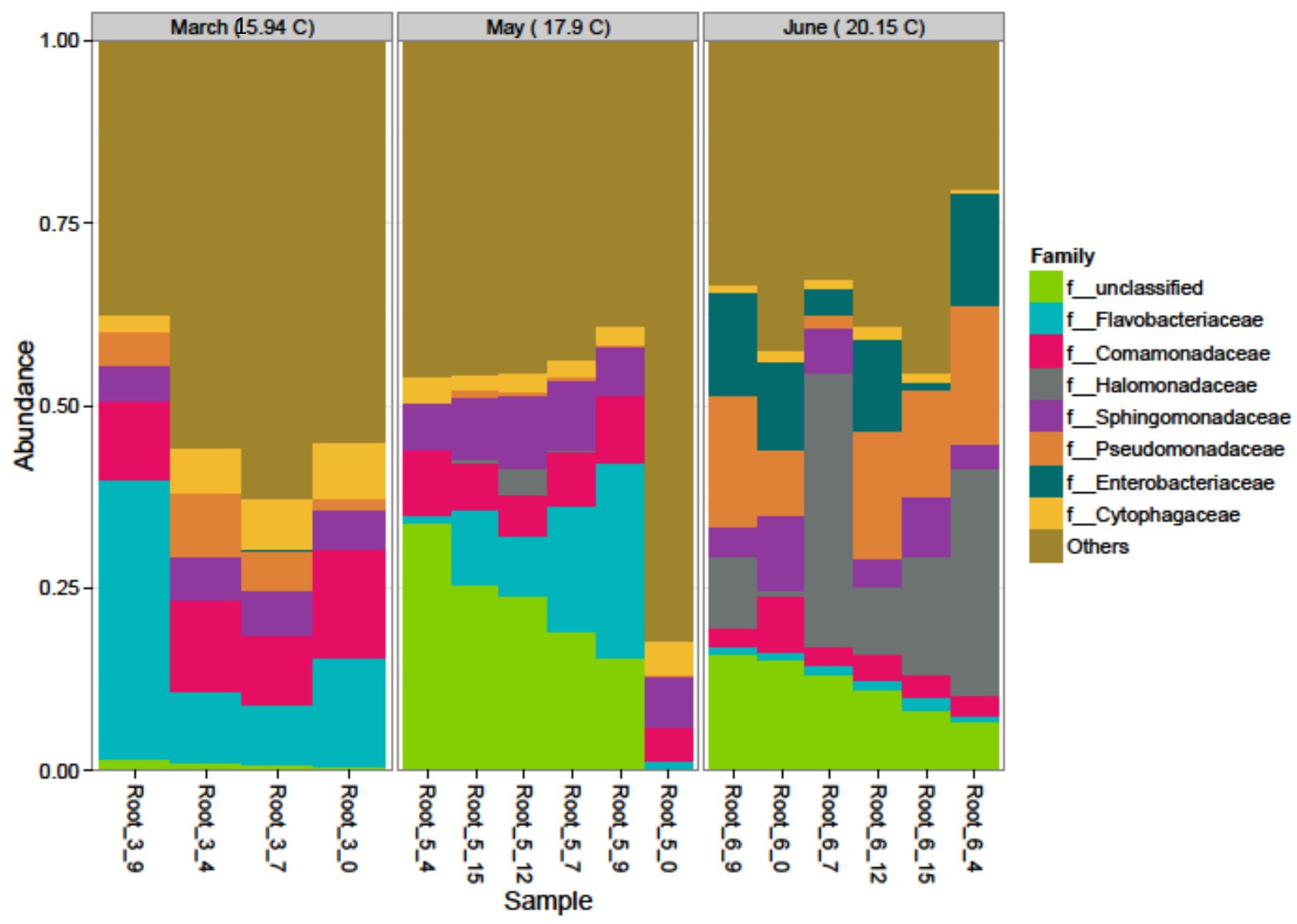

Fig. 2D 


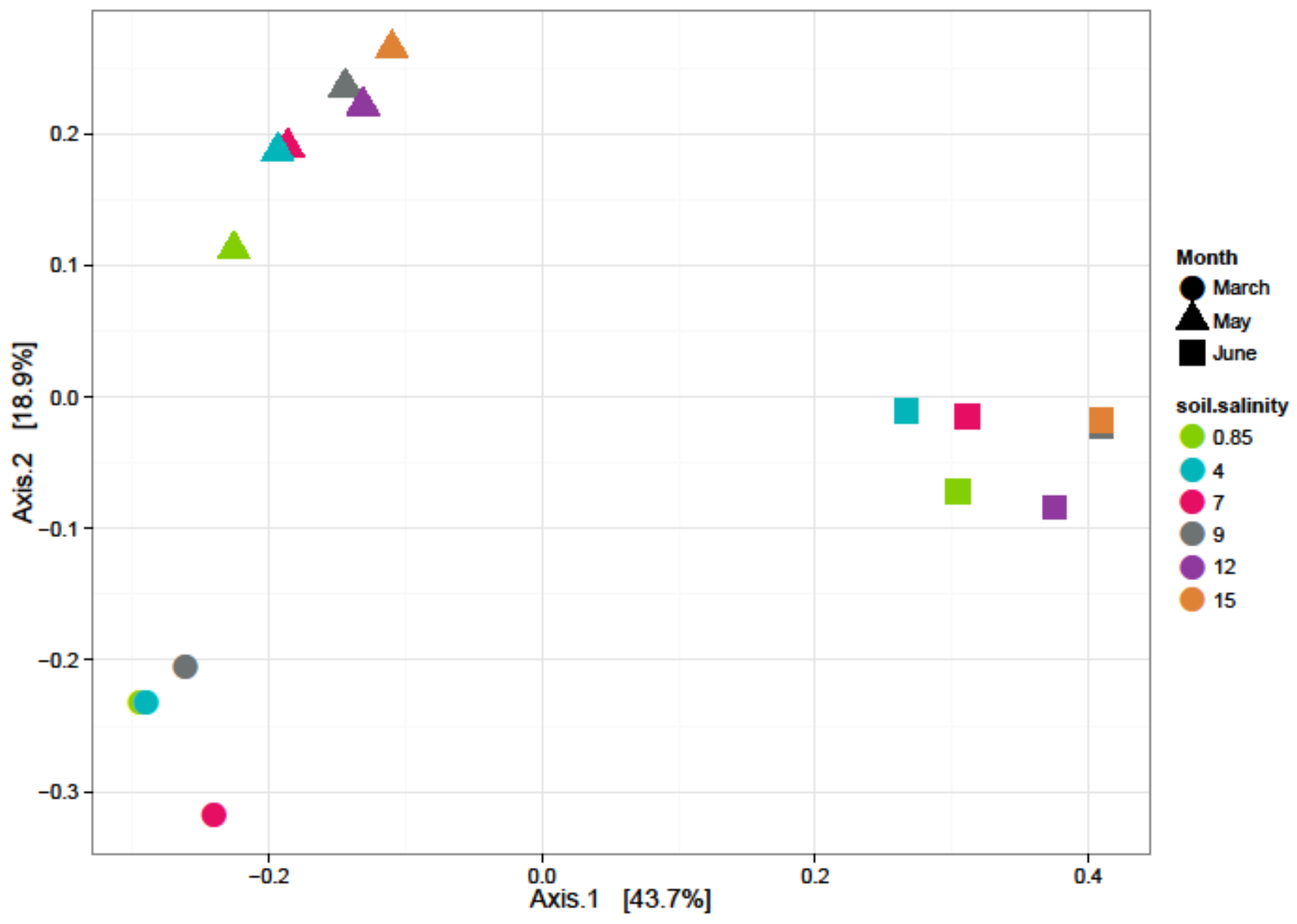

Fig. 3A 


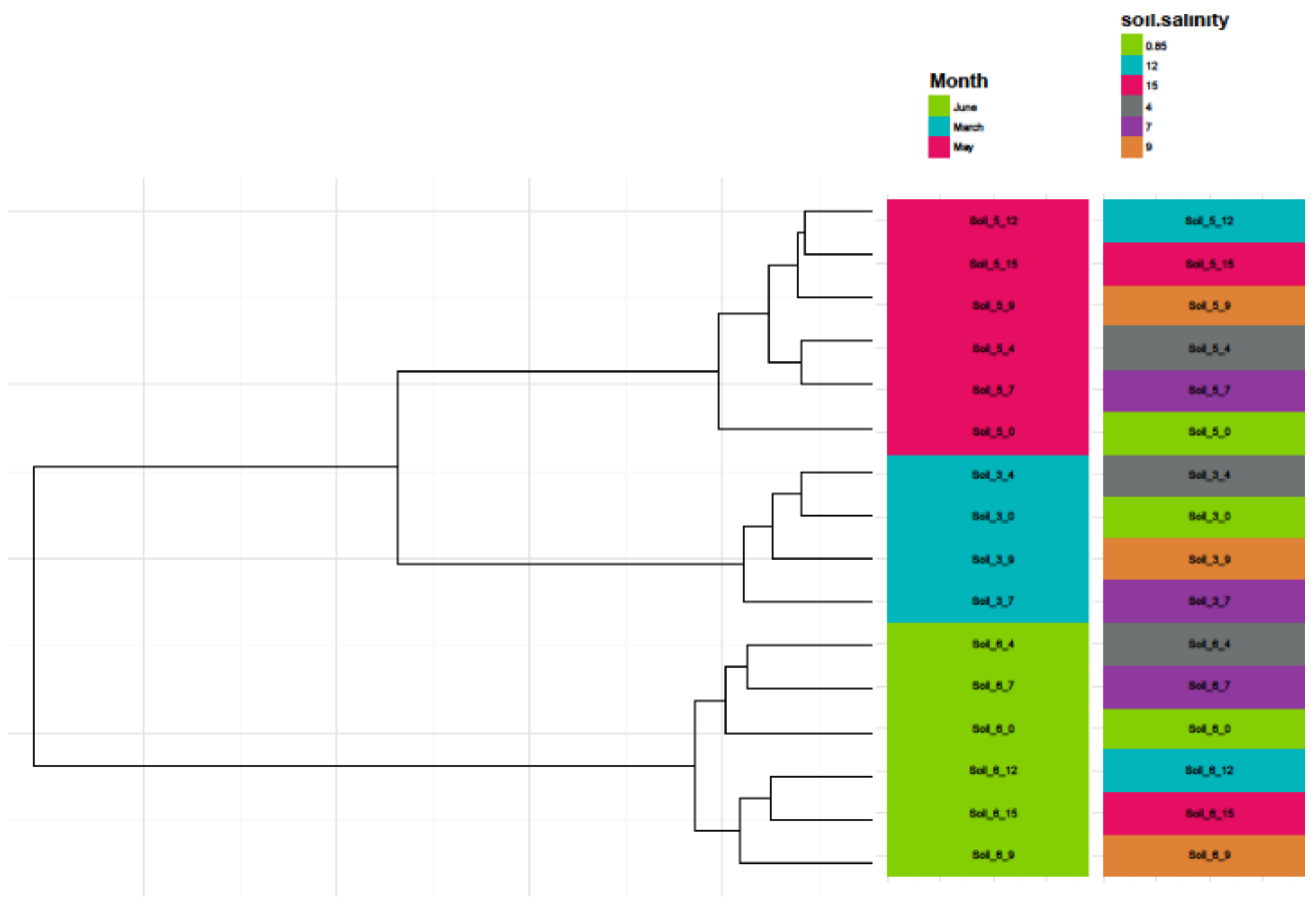

Fig. 3B 


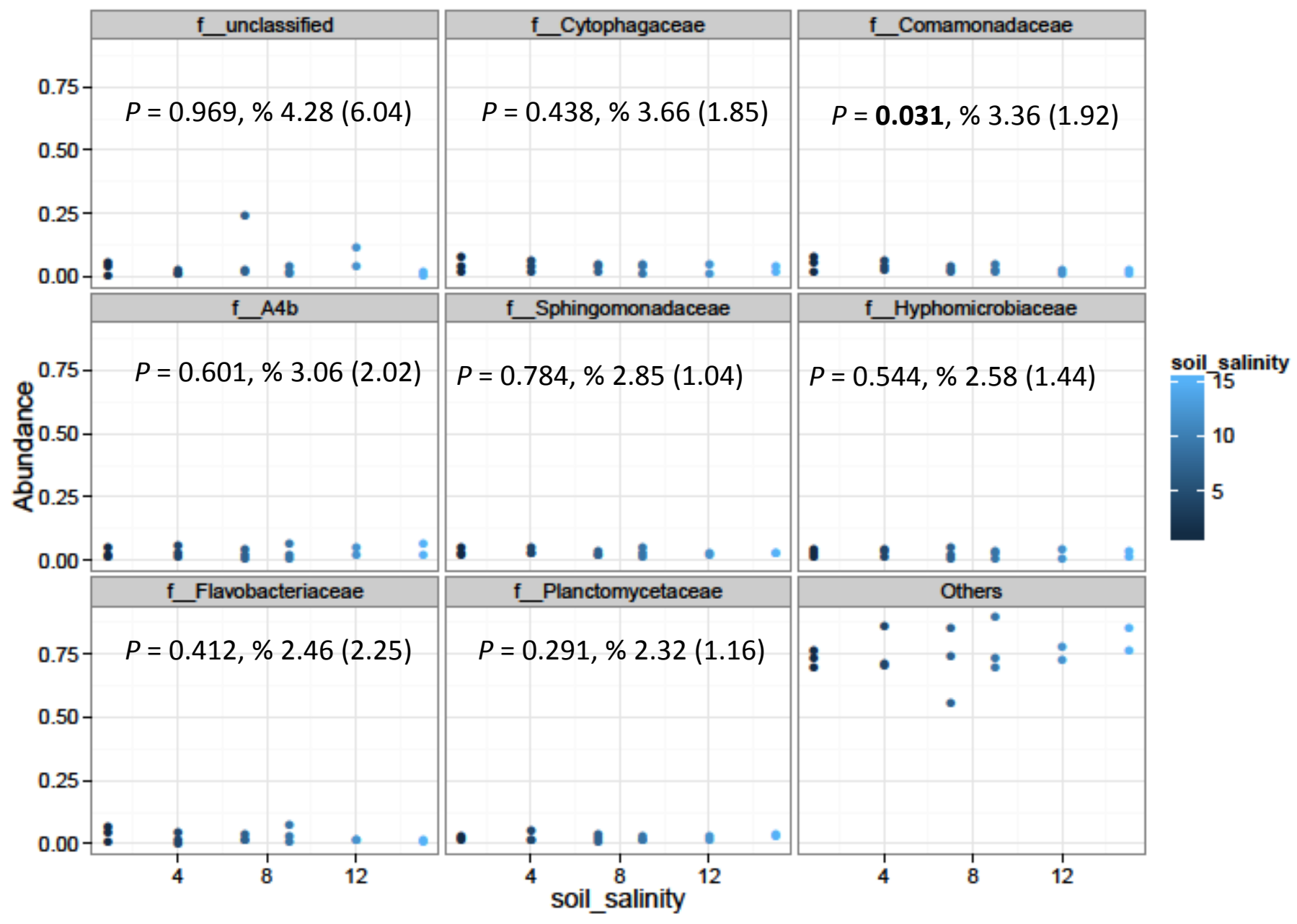

Fig. 3C 


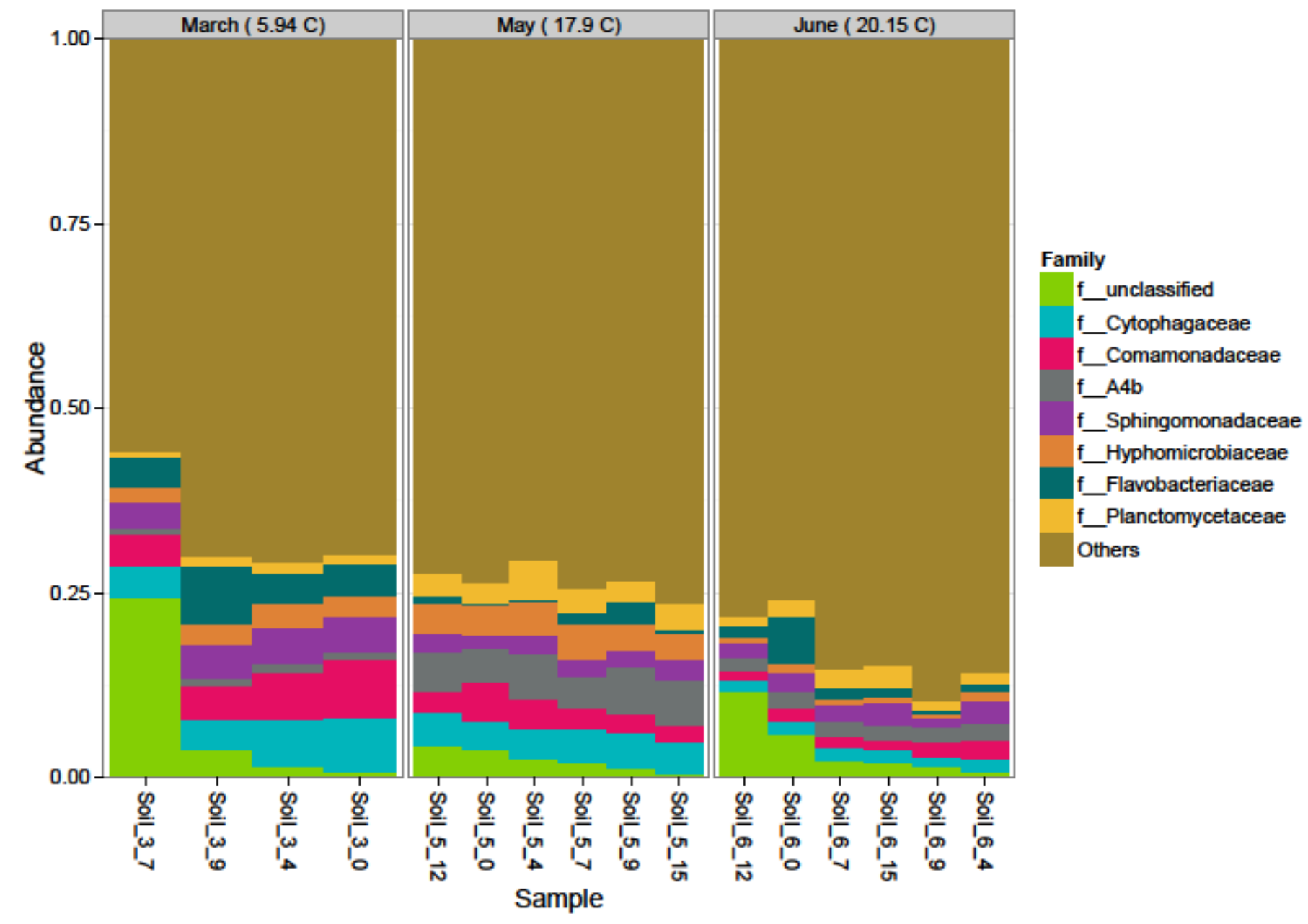

Fig 3D: 


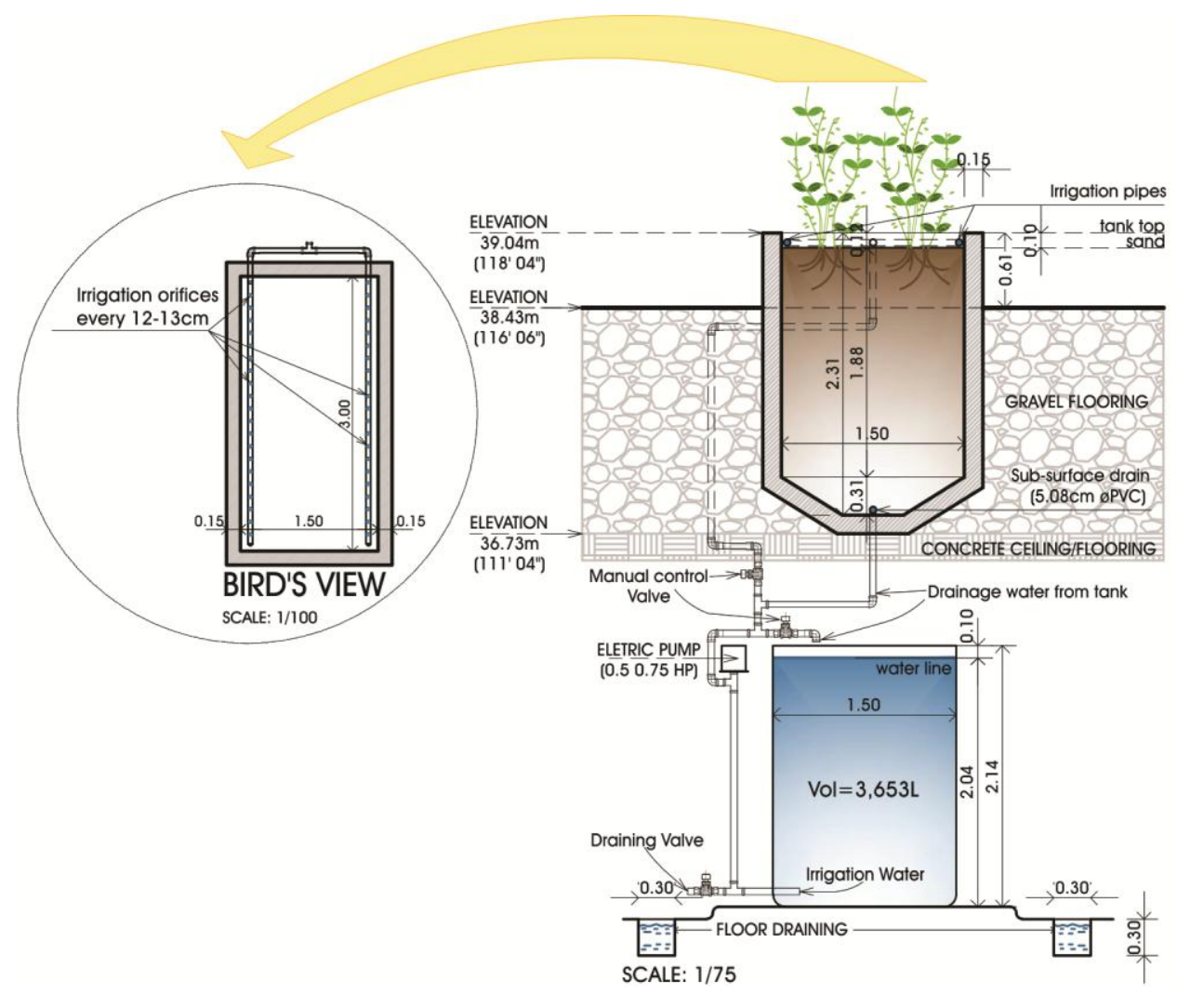

Fig.1S 


\section{${ }^{*}$ Graphical Abstract}

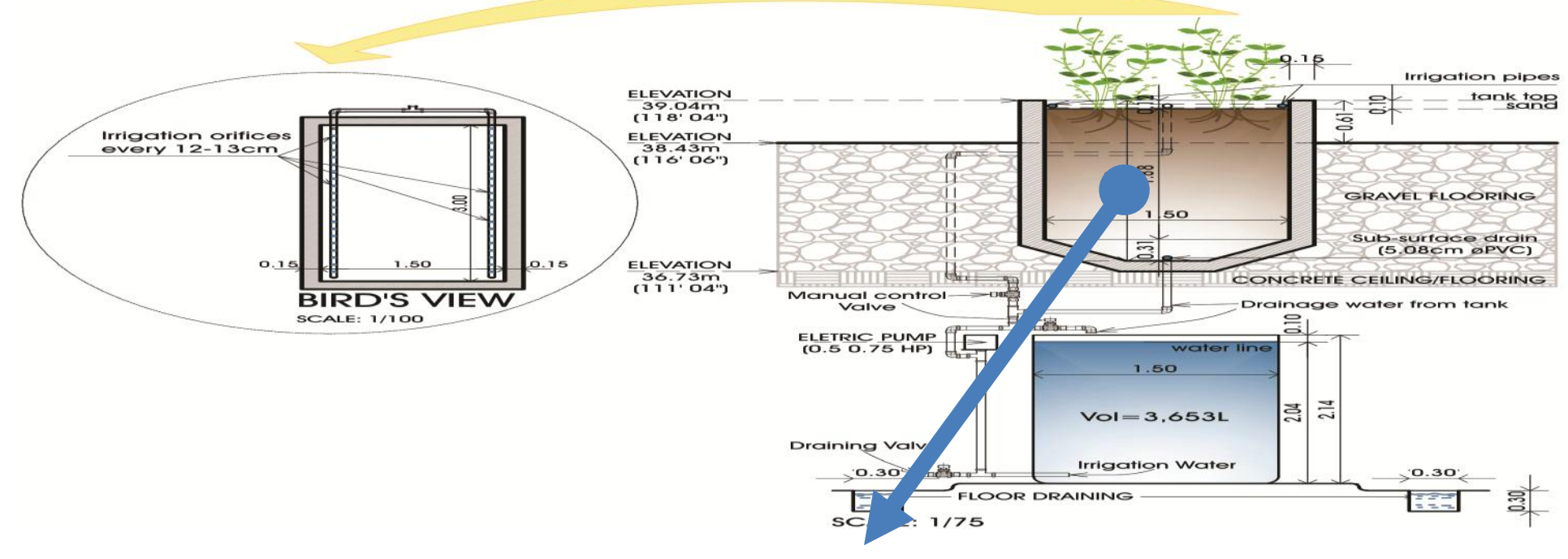

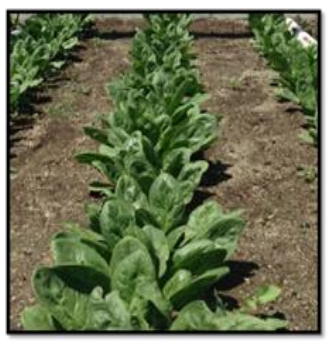

control

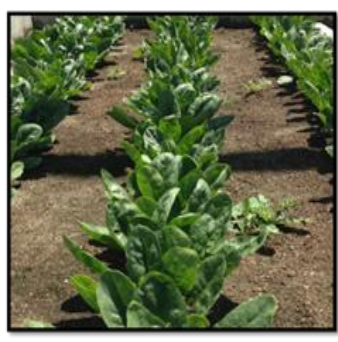

$4 \mathrm{dS} \mathrm{m}^{-1}$

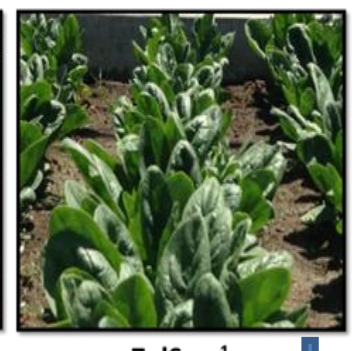

$7 \mathrm{dS} \mathrm{m}^{-1}$

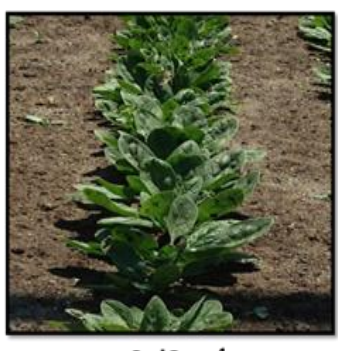

$9 \mathrm{dS} \mathrm{m}^{-1}$

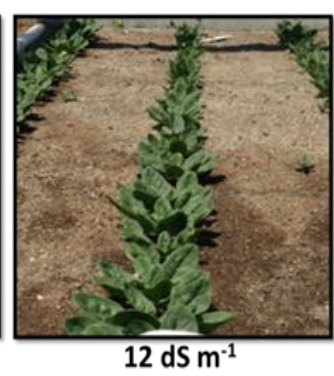

$12 \mathrm{dS} \mathrm{m}^{-1}$

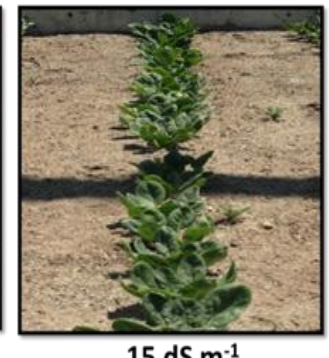

$15 \mathrm{dS} \mathrm{m}^{-1}$

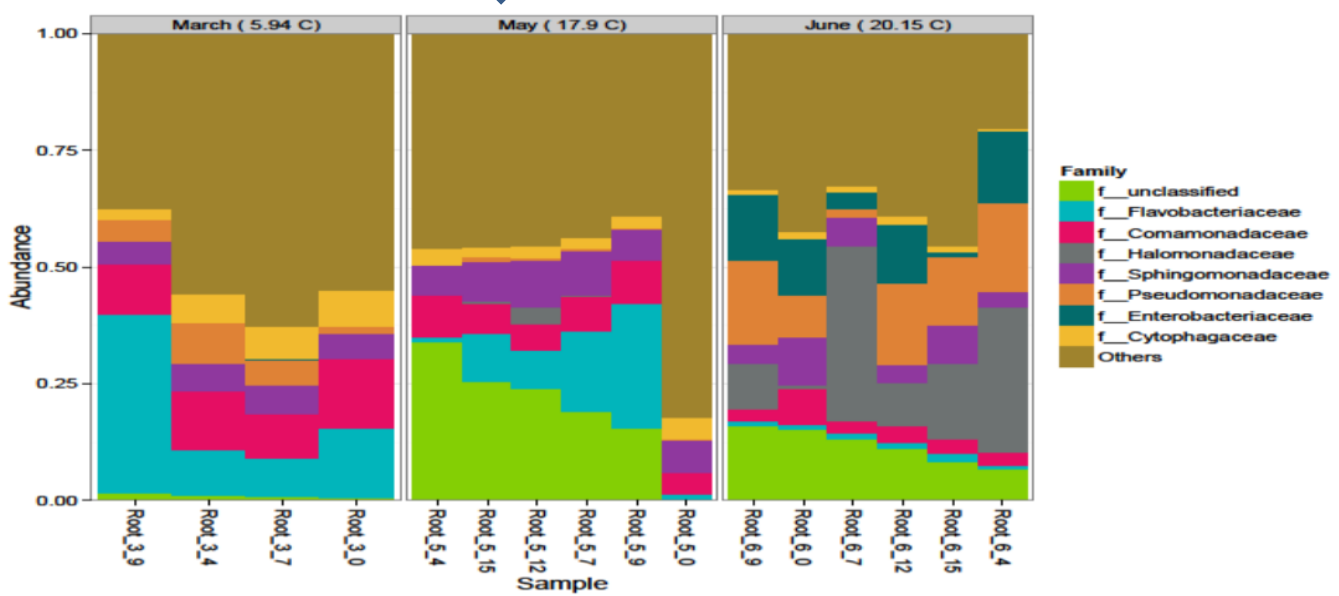

